\title{
Lineage Analysis Reveals Neurotransmitter (GABA or Glutamate) but Not Calcium-binding Protein Homogeneity in Clonally Related Cortical Neurons
}

\author{
M. C. Mione, C. Danevic, P. Boardman, B. Harris, and J. G. Parnavelas \\ Department of Anatomy and Developmental Biology, University College London, London WC1E 6BT, United Kingdom
}

Studies of cell lineage in the rat cerebral cortex have provided new insights into the mechanisms of neuronal and glial determination. They have shown that clonally related cells, marked with retrovirus injection at embryonic day 16 (E16), express the same glial or neuronal phenotype, suggesting that separate progenitors for each of these cell phenotypes exist in the ventricular zone at that stage of corticogenesis. However, it is not known if such committed progenitors are present in the ventricular zone before E16. Another important question concerns which neurochemical features are shared by clonally related cells of the adult cerebral cortex.

In this study we have addressed the first question by injecting a retroviral vector expressing $\beta$-galactosidase into the telencephalic ventricles of rat embryos at different stages (E14-E 19). In order to classify clonally related neurons in the cerebral cortex of these rats, we have used postembedding immunohistochemistry for the amino acid neurotransmitters glutamate, aspartate, and GABA. Glutamate and GABA immunoreactivity marked nonoverlapping populations of cells that corresponded to the pyramidal and nonpyramidal neuron types of the rat cerebral cortex. Clonally related neurons, marked by retrovirus injection at any day between E14 and E19, homogeneously expressed one or other phenotype and accordingly displayed glutamate or GABA immunoreactivity. This finding indicates that committed progenitor cells for pyramidal and nonpyramidal neurons are present in the ventricular zone before E16. To investigate whether lineage dictates other features in clonally related neurons, we performed an immunohistochemical analysis for the calcium-binding proteins calbindin, parvalbumin, and calretinin in clusters of clonally related nonpyramidal neurons. The same calcium-binding protein was rarely found in members of the same cluster, suggesting that lineage does not control the expression of calcium-binding proteins in cortical nonpyramidal neurons.

Received Feb. 26, 1993; revised May 18, 1993; accepted June 30, 1993

We are grateful to Marion E. Cavanagh and Eva Franke for their contributions at the early stages of this work. We thank Professor M. R. Celio for the generous gift of the anti-parvalbumin and anti-calretinin antibodies, Dr. S. W. Davies for the anti-calbindin antibody, and Dr. M. B. Luskin for the retrovirus-producing cell colony. We also thank Michael Recce for advise on the statistics, John Cavanagh for writing the computer program to test random distribution, and Marion Cavanagh and Dr. Stephen W. Davies for carefully reading the manuscript. Financial support was provided by Medical Research Council Grant G9006412N, and the Wellcome Trust.

Correspondence should be addressed to Dr. Marina Mione, Department of Anatomy and Developmental Biology, University College London, Gower Street, London WC1E 6BT, U.K.

Copyright (c) 1994 Society for Neuroscience $0270-6474 / 94 / 140107-17 \$ 05.00 / 0$
As a result of examining a large number of clonally related neurons from brains injected at different ages, we observed remarkable differences in number and laminar distribution of pyramidal and nonpyramidal neurons marked with retrovirus. Clusters of nonpyramidal neurons were usually compased of two or three cells, and resided in the cortical layers that were just being generated at the time of injection. Clusters of pyramidal neurons were larger and dispersed in several layers in the earlier injections; their size and laminar distribution were progressively reduced for later injections. These observations suggest the existence of different mechanisms that generate the pyramidal and nonpyramidal neurons of the cerebral cortex.

[Key words: retrovirus, cerebral cortex, lineage, pyramidal neurons, interneurons, phenotype, GABA, glutamate, aspartate, parvalbumin, calbindin, calretinin]

The two main classes of neurons in the cerebral cortex, the pyramidal and nonpyramidal cells, have different neurochemical and physiological properties. The former are the projection neurons, which are known to exert potent excitatory action in the cortex and in subcortical target areas by releasing the excitatory amino acids L-glutamate (Glu) or L-aspartate (Asp) (Fagg and Foster, 1983; Streit, 1984; Dori et al., 1992). The nonpyramidal neurons are the cortical interneurons, which, by releasing the inhibitory neurotransmitter GABA, have a powerful inhibitory effect on neurons of the cortex (Fagg and Foster, 1983; Sillito, 1984). In the mature cerebral cortex, the two populations of neurons can be reliably marked by the presence of the classical neurotransmitters Glu or GABA. The numerical relationship between these two neuronal cell types is very similar in different cortical areas and in various mammalian species (Rockel et al., 1980; Hendry et al., 1987; Meinecke and Peters, 1987) with a large preponderance of pyramidal over nonpyramidal neurons, suggesting that their production is regulated by rigidly controlled mechanisms. Any imbalance of excitatory and inhibitory stimuli can seriously alter cortical functions leading to epileptogenesis (T'raub et al., 1987) and degeneration of neuronal circuits (Mattson and Kater, 1989).

All neurons in the cerebral cortex are generated from progenitor cells in the ventricular zone and populate the six cortical layers, in an inside-out order, according to the time they are produced (Berry and Rogers, 1965; Rakic, 1974; Raedler et al., 1980; Luskin and Shatz, 1985). In the rat, neurogenesis takes place during the last week of gestation (E14-E21) (Rickmann et al., 1977; Miller, 1985). Several lines of evidence suggest that commitment of cortical neurons to a particular phenotype takes 
place in the ventricular zone, where progenitor cells are actively dividing. For example, separate progenitor cells for both neocortical and hippocampal ncurons and glia arc thought to bc present in the ventricular zone of rodents by E16 (Luskin et al., 1988, 1993; Barfield et al., 1990; Grove et al., 1992). Commitment to specific cortical areas is revealed by the expression of the limbic system-associated membrane protein in young postmitotic neurons destined for the limbic cortex as early as E14 (Levitt, 1984; Barbe and Levitt, 1991), or by the expression of a somatosensory-associated antigen in embryonic dividing cells and their progeny grown in culture (Arimatsu et al., 1992). Commitment to a laminar position also occurs in the ventricular zone before the final mitotic division (McConnell and Kaznowski, 1991).

Does cell lineage have a role in determining neuronal identity? In the invertebrate CNS, where it is possible to identify specific neuronal stem cells and to follow their progeny during development, it has been shown that lineage plays an essential role in determining neuronal phenotype (Huff et al., 1989; Witten and Truman, $1991 \mathrm{a}, \mathrm{b}$; Shankland and Martindale, 1992; Sternberg et al., 1992). Such studies have provided several examples of the complex mechanisms through which lineage may control cell phenotype. Apart from producing committed precursors, lineage may confer different phenotypes to the progeny in accordance with their birth order or it may distribute receptors for local signals unequally between the progeny.

To test the hypothesis that the determination of neuronal identity in the CNS is regulated by lineage, rather than by factors intervening after a neuron has become postmitotic, the use of retroviral markers has proven very fruitful. In the chick optic tectum, a single precursor cell was shown to give rise to neurons and glia (both astrocytes and radial glia) (Gray et al., 1988; Galileo et al., 1990; Gray and Sanes, 1992); in the avian spinal cord, the neuroepithelial cell generates motor neurons, other types of neurons, astrocytes, and probably oligodendrocytes (Leber et al., 1990). However, in both cases migration along different pathways was correlated with the adoption of a distinct phenotype (Gray et al., 1990; Leber and Sanes, 1990; Gray and Sanes, 1991, 1992). These findings raise questions about how multipotent progenitors produce and distribute different cell types. In the vertebrate retina, progenitor cells infected with a retroviral marker have been shown to give rise to clones containing different combinations of retinal cell types (Turner and Cepko, 1987; Turner et al., 1990). These data have been interpreted as a proof of lineage-independent determination of cell types in the murine retina. However, a careful consideration of the same results (Williams and Goldowitz, 1992) pointed to a progressive restriction of multipotentiality along the lineage, as already shown with other techniques (Reh, 1992). These reports show that finding multiple phenotypes after marking precursor cells does not rule out the possibility that lineage may control cell phenotype through the birth order of the progeny.

Studies on neuronal lineages in the cerebral cortex, using retroviruses as lineage tracers, have provided conflicting results. Some authors, who identified cells on the basis of their appearance at the light microscope, reported that both pyramidal and nonpyramidal neurons can be found in single clones (Price and Thurlow, 1988; Walsh and Cepko, 1988). Others, using ultrastructural analysis, found a striking homogeneity for pyramidal and nonpyramidal neurons in clusters of clonally related cells labeled by injections of retrovirus at E15 and E16 (Parnavelas et al., 1991; Luskin et al., 1993). This discrepancy could be due to the methods of analysis applied. On the one hand, examination of labeled cells with the light microscope does not usually reveal sufficient morphological detail to allow uncquivocal classification of cell phenotype. On the other hand, few clusters of clonally related cells have so far been subjected to ultrastructural analysis. It is clear that insight into the genetic and developmental mechanisms that give rise to the fully differentiated and highly specialized cell types of the cerebral cortex requires both reliable classification as well as examination of a large number of cases. A further point of concern has been introduced recently by the report of a more widespread migration of clonally related neurons in the rat cerebral cortex (Walsh and Cepko, 1992) than had previously been postulated. However, this finding does not alter the validity of the use of the retrovirus technique to the study of lineage relationships in the cerebral cortex, as will be discussed later.

Our approach was to use postembedding immunohistochemistry to localize the inhibitory neurotransmitter GABA and the excitatory neurotransmitters Glu and Asp in clonally related cells. This approach has allowed us to classify reliably (as confirmed by ultrastructural analysis of the same cells) all clusters of clonally related $\beta$-galactosidase-positive $(\beta$-gal +$)$ cells in lightly infected brains injected with retrovirus at various gestational stages between E14 and E19. The findings arising from this analysis support the hypothesis that lineage plays an important role in determining the phenotype of cortical neurons and the neurotransmitter(s) they use. We also performed a further immunohistochemical analysis in CABA-immunoreactive clonally related neurons. It consisted of the localization of three calcium-binding proteins, parvalbumin (Parv), calbindin (Calb), and calretinin $(\mathrm{Cr})$, that are thought to characterize selectively subpopulations of cortical nonpyramidal neurons (Demeulemeester et al., 1989; Celio, 1990; Van Brederode et al., 1990, 1991). The presence of these calcium-binding proteins in intrinsic neurons has been correlated with specific afferent systems (Freund and Gulyás, 1991; Hornung and Celio, 1992) and with common physiological properties (Baimbridge et al., 1992; Lledo et al., 1992). We were interested whether these features could also be dictated by lineage. In this case, our study failed to demonstrate the same calcium-binding protein(s) in clonally related nonpyramidal neurons.

Finally, the cxamination of the distribution of ccll types labeled by retrovirus injections at different embryonic ages provides new information about the possible mechanisms that produce the cortical pyramidal and nonpyramidal neuronal cell types.

Some of these results have been published in abstract form (Mione et al., 1992).

\section{Materials and Methods}

Production of retrovirus. The BAG-retrovirus vector, containing the reporter gene encoding for Escherichia coli $\beta$-galactosidase (Price et al., 1987), was used in these studies. The replication-defective recombinant retrovirus was obtained by collecting and filtering the culture medium of psi 2 helper cells that had been transfected with BAG retrovirus. These virus-producing cells, purchased from ATCC (Rockville, MD) and subcloned to generate colonies producing a higher titer of retroviral particles, were generously given to us by Dr. M. B. Luskin (Emory University). Typically the medium contained $3 \times 10^{6}$ infectious viral particles/ml as determined according to published methods (Luskin et al., 1988). The absence of helper virus from these cultures was periodically assessed as described by Luskin et al.(1988).

Surgery. Female Sprague-Dawley rats were mated at night and the first day of pregnancy, as determined by the presence of a vaginal plug, 
was designated embryonic day 1 (El) in accordance with earlier studies of cortical neurogenesis using ${ }^{3} \mathrm{H}$-thymidine autoradiography (Cavanagh and Parnavelas, 1988; Altman and Bayer, 1990). It should be noticed that some recent lineage studies (Luskin et al., 1988; Price and Thurlow, 1988; Walsh and Cepko, 1988) have designated the first day of pregnancy as E0. Pregnant rats of different gestational ages between E14 and E19 were utilized in this study. They were anesthetized with halothane, and after exposing the uterine horns through a laparotomy, a fiber optic light source was used to transilluminate fetuses through the uterine wall, to visualize the cerebral ventricles. Approximately $1 \mu \mathrm{l}$ of solution, containing 500-1000 infectious viral particles, $0.5 \mu \mathrm{g}$ of polybrene, and $0.1 \mu \mathrm{g}$ of fast green dye, was injected into the telencephalic ventricles of each fetus using a 30 gauge needle attached to a $25 \mu$ l Hamilton microsyringe. After all the fetuses were injected, the abdominal wall was sutured and the animals allowed to recover. Pups were born and grew normally.

Histochemistry and tissue processing. At about 2 months of age, the injected pups were deeply anesthetized with ether and perfused transcardially with a mixture of $4 \%$ paraformaldehyde and $0.2 \%$ glutaraldehyde in $0.1 \mathrm{M}$ phosphate buffer $(\mathrm{PB}), \mathrm{pH}$ 7.4. Brains were removed and placed in the same fixative for up to $30 \mathrm{~min}$, and then transferred to PB. The cerebral hemispheres were separated, and $100-\mu \mathrm{m}$-thick sections were cut serially in the coronal plane using a Vibrotome. These sections were incubated overnight at room temperature in X-Gal (Sigma, U.K.), as described by Sanes et al. (1986), to reveal $\beta$-gal+ cells, processed for electron microscopy, and flat-embedded in Araldite as described previously (Luskin et al., 1993).

Selecting clusters of clonally related cells. The $\beta$-gal + cells in both hemispheres were mapped in camera lucida drawings of serially arranged sections. Every labeled cell was assigned to a cortical area according to Krieg (1946a) and Zilles (1985), and to a layer according to Krieg (1946b). In accordance with a recent report (Luskin et al., 1993), we considered discrete clusters of closely spaced $\beta$-gal + cells (contained within a $500 \mu \mathrm{m}$ strip of cortex and separated from any other labeled cell by at least $500 \mu \mathrm{m}$ ) to be derived from the same progenitor cell, that is, to belong to the same clone. The precise spatial organization of cach cluster was mapped using a computer-aided microscope system for superimposition of serial sections (Neurotrace, InterAction Co., Cambridge, MA).

In view of the possibility of widespread dispersion of cortical clones, as reported recently by Walsh and Cepko (1992), we included in our study only hemispheres containing a limited number (one to seven) of widely spaced clusters of $\beta$-gal + cells, and displaying few isolated labeled cells. Using these restrictive criteria, we believe that we have greatly reduced the risk of "lumping" error, that is, the possibility of including $\beta$-gal + cells from different progenitors in a single cluster (Walsh and Cepko, 1992). We evaluated the probability that a random distribution of isolated $\beta$-gal + cells in the volume of an adult rat cerebral cortex could result in the superimposition of randomly dispersed neurons and preexisting clusters. The distribution of randomly dispersed $\beta$-gal + cells can bc described with a binomial distribution, which gives an estimate of the probability for superimposing preexisting clusters. In this case, the probability of not superimposing randomly dispersed cells and preexisting clusters is the ratio of the volume of the cortex that is not labeled to the total volume. We applied the formula

$$
P=1-\left[\left(V_{t}-V_{x c}\right) / V_{t}\right]^{n},
$$

where $P$ is the probability of superimposition of $n$ randomly dispersed cells and $x$ preexisting clusters, $V$, is the volume of the cerebral cortex in one hemisphere of an adult rat, and $V_{x c}$ is the volume of cortex occupied by $x$ clusters of $\beta$-gal + neurons. The volume of the cortex in one hemisphere was taken to be $125 \mathrm{~mm}^{3}$, half of the total volume of the whole cortex as calculated by Korbo et al. (1990). The volume of each cluster corresponded, by our definition, to the volume of a cone with radius of $250 \mu \mathrm{m}$ and height of $2 \mathrm{~mm}$ (the thickness of the cortex of an adult rat is approximately $1.7 \mathrm{~mm}$ ), that is, $0.1308 \mathrm{~mm}^{3}$. To evaluate $n$, we considered that $50 \%$ of all clustered $\beta$-gal + neurons could be unrelated to their neighboring cells in the clusters, and resulted by the casual aggregation of randomly dispersed neurons. This percentage is a generous overestimation of the proportion of randomly dispersed cells when compared with the percentage reported by Walsh and Cepko (1992); in their study, they estimated that about $25 \%$ of all clones were not clustered. Using this calculation, we found that the probability of superimposition of randomly dispersed neurons and preexisting clusters was between $0.2 \%$ and $14.6 \%$. This probability rose with the number of clusters and with the number of cells per cluster, thus being higher in brains injected with retrovirus at E14, where the clusters were composed of a large number of cells. In $45 \%$ of our experiments (10 of 22), the probability of superimposition of randomly dispersed neurons and preexisting clusters was less than $1 \%$; in $36 \%$ of experiments ( 8 of 22 ) such probability was less than $5 \%$, and only in 2 of 22 cxpcriments (corresponding to brains injected at E14) this probability was over $10 \%$. We also ran a computer program that simulates random positioning of clusters and isolated cells. To give an example, in the hemisphere with the largest number of $\beta$-gal + cells there were six clusters; they were considered to be composed of half clonally related and half clonally unrelated cells. The total number of cells in these clusters was 40 . Thus, we distributed randomly 20 cells (occupying a volume of $5.22 \times 10^{-7}$ $\mathrm{mm}^{3}$ each) and six clusters (occupying $0.1308 \mathrm{~mm}^{3}$ each) in one hemisphere $\left(125 \mathrm{~mm}^{3}\right)$ in 100,000 computer simulations. The percentage of hits between isolated cells and clusters was $12 \%$, a value similar to that obtained with the hinomial test. Slightly lower values were obtained with the computer simulations of all our experiments compared with the statistical analysis; this approach gave a range of probabilities of superimposition of randomly dispersed cells and preexisting clusters between $0.1 \%$ and $12 \%$. Thus, in our worst cases, random dispersion could be responsible of having placed at the most 2 cells of 40 in the wrong clusters. However, we are aware that we may not be dealing with the entire clone (Walsh and Cepko, 1992); thus, we refer to them as clusters of clonally related cells. All of the clusters analyzed in this study contained neurons; those composed exclusively of glial cells are listed, but their phenotypic characterization will be the subject of a separate report.

Postembedding immunohistochemistry. Every $\beta$-gal + cell of every cluster selected for analysis was sectioned so as to obtain at least 10 semithin $(0.5 \mu \mathrm{m}$ thick) sections to be used for immunohistochemistry and a number of ultrathin sections for ultrastructural examination. Immunohistochemical and electron microscopical examinations were carried out independently by two of us. The ultrastructural criteria used to classify neuronal cell types have long been established in the literature, and were the same as those used in recent lineage studies in the rat cerebral cortex (Parnavelas et al., 1991; Luskin et al., 1993). Prior to processing semithin sections for immunohistochemistry, a drawing of each section was made with a drawing tube, documenting the location of the $\beta$-gal + cells, adjacent cells, and any landmarks (i.e., blood vessels), to ensure cell identification following immunostaining. The $\beta$-gal blue reaction product was soluble in propylene oxide and disappeared during processing. Semithin sections were processed for immunohistochemistry according to the method described by DeFelipe and Jones (1992). Briefly, resin was removed from sections using a mixture of absolute alcohol and propylene oxide (Maxwell, 1978). Three consecutive sections of the same cell were incubated overnight with one of the following polyclonal antisera: anti-GABA (Sigma), anti-Glu, and anti-Asp (both from Arnell, NewYork, NY; Hepler et al., 1988), all diluted 1:2000 in PBS containing $0.5 \%$ Triton X-100. They were then processed with the a vidin-biotin-peroxidase method using the $\mathrm{ABC}$ kit from Vector (U.K.), and reacted in diaminobenzidine (DAB) and hydrogen peroxide. Sections of cells that were GABA immunoreactive were incubated with polyclonal anti-Parv, anti-Cr (donated by M. Celio, University of Friburg; Kägl et al., 1987; Schwaller et al., 1993), or anti-Calb (donated by S. W. Davies, University College London; Jones and Hendry, 1989), all diluted $1: 500$ in PBS, containing $0.5 \%$ Triton X-100, and processed as above with the exception that $0.03 \%$ nickel ammonium sulfate was added to the DAB solution to intensify the reaction products. After immunohistochemistry, sections were dehydrated and mounted in DPX.

\section{Results}

We studied 47 clusters of clonally related neurons from 11 hrains using immunohistochemistry and electron microscopy. Table 1 shows the distribution, location, size, and composition of all clusters and the average number of isolated $\beta$-gal + cells for each age of injection. All but one cluster of the 47 examined were composed of neurons only. The one exception was a mixed cluster consisting of pyramidal neurons and astrocytes. However, clusters containing exclusively glial elements were present (see Table 1) and their analysis will be the subject of a separate report. 


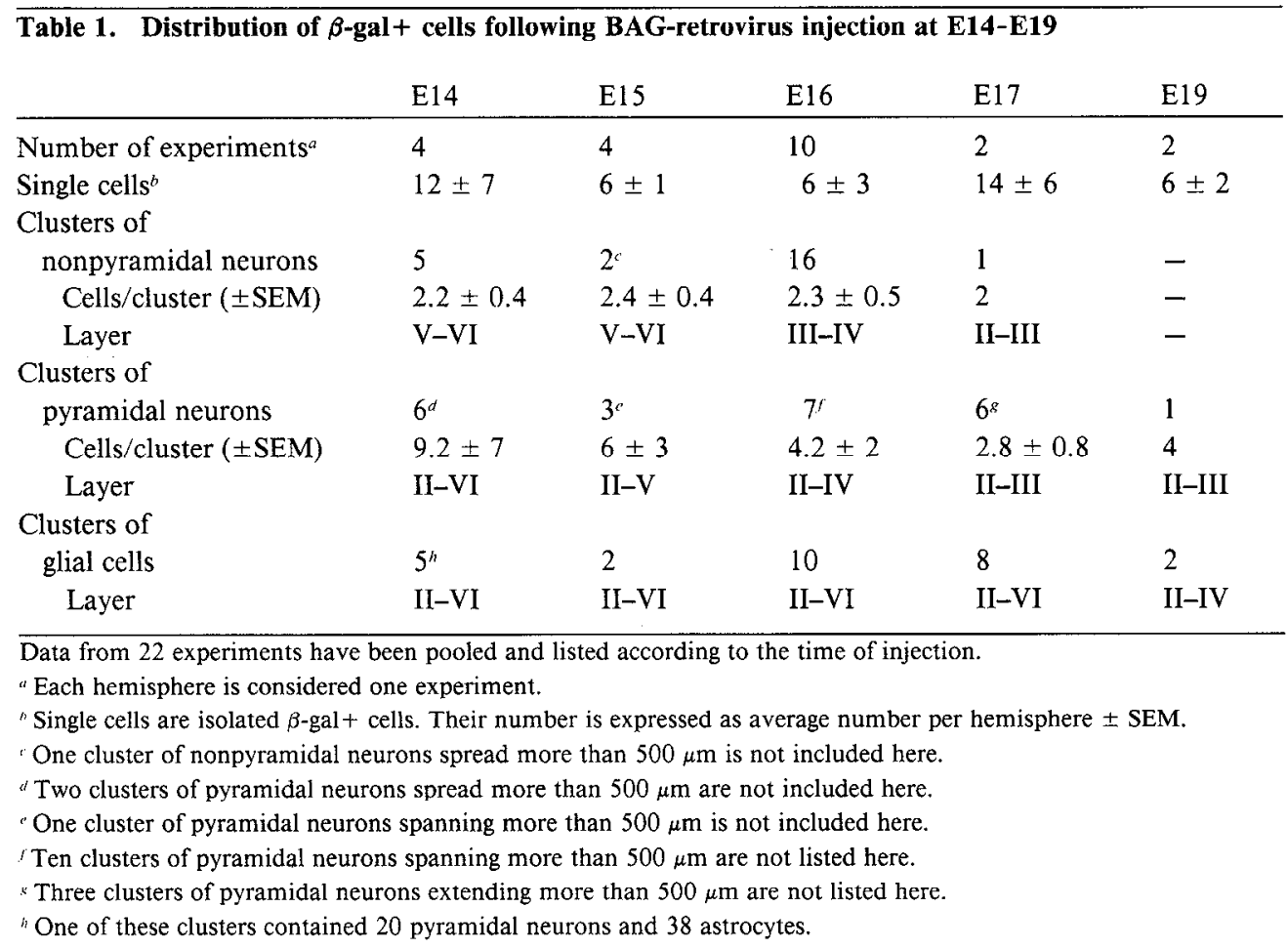

Before giving a detailed account of our observations on these 47 clusters, the following general points can be made; included are observations carried out in brains not listed here. (1) With only one exception, all brains injected between E14 and E17 contained labeled glia and nonpyramidal and pyramidal neurons. Brains injected at E18 or later in gestation contained progressively fewer clusters of nonpyramidal neurons and, for injections after E20 (E21 and early postnatal period), the only $\beta$-gal + cells found were glia (data not shown). (2) Nonpyramidal neurons marked by retrovirus injections at E14 and E15 were confined to the infragranular layers, while they mainly populated layers II-IV following injections at E16 or later. (3) Labeled pyramidal neurons were dispersed in all layers in brains injected in the earlier stages of neurogenesis (E14-E16), but were confined to layers II and III following later injections. (4) The majority of clusters of clonally related nonpyramidal neurons were contained in one or two adjacent layers, thus indicating that they may have been generated at the same time. This observation, together with the small size of these clusters (typically two or three cells), suggests that nonpyramidal neurons may be generated by the final division of their progenitors.

\section{Identification of immunoreactive elements in Araldite- embedded sections of cerebral cortex}

The postembedding immunohistochemical protocol gave a highly reproducibile pattern of staining for all three neurotransmitter substances investigated. Moreover, the distribution of GABA-, Asp-, and Glu-immunoreactive elements was in accordance with previous reports in which preembedding immunohistochemical protocols were applied (Conti et al., 1987a; Meinecke and Peters, 1987; Dori et al., 1989). The only exception was the degree of coexistence of Glu and Asp immunoreactivity in pyramidal neurons. A previous study in the somatosensory cortex of the rat (Conti et al., 1987b) reported that approximately $10 \%$ of all Glu- and Asp-immunoreactive neurons stained with both an- tisera, but in our samples this proportion was over $50 \%$. We were particularly concerned about two possible sources of error that could invalidate our classification: (1) the localization of Glu immunoreactivity in glial cells (Ottersen and Storm-Mathisen, 1984) and (2) the presence of Asp immunoreactivity in cortical nonpyramidal neurons (Dori et al., 1989). In our preparations, glial cells, as assessed with electron microscopy (Parnavelas et al., 1983), were not immunoreactive for Glu, Asp, or GABA. A relatively small number of GABA-immunoreactive neurons (about 5\%) were also immunoreactive for Asp in accordance with previous studies in the rat visual cortex (Dori et al., 1989). These neurons showed features typical of nonpyramidal neurons when observed with the electron microscope (for description of features, see Parnavelas et al., 1991; Luskin et al., 1993). We should add that GABA immunoreactivity was never visualized in pyramidal neurons, nor was Glu immunoreactivity ever present in nonpyramidal neurons. Thus, the combination of the immunostaining for all three amino acids in the same cell permits for reliable classification of every neuron. The possible combinations are listed below and have been confirmed by ultrastructural analysis of more than 200 cells, as part of clusters of clonally related cells or as single isolated $\beta$-gal + elements: (1) GABA + , Asp - , Glu $-=$ nonpyramidal neuron; (2) GABA +, Asp +, Glu- = nonpyramidal neuron; (3) GABA-, Asp + , Glu+ = pyramidal neuron; (4) GABA--, Asp-, Glu+ $=$ pyramidal neuron; (5) GABA - , Asp + , Glu $-=$ pyramidal neuron; (6) GABA-, Asp -, Glu- = glia or nonpyramidal neuron.

\section{Distribution of $G A B A, A s p$, and Glu immunoreactivity in clonally related neurons}

One hundred seventy-five of the $\beta$-gal + neurons examined in this study made up 47 clusters, 23 containing only pyramidal neurons and 24 containing nonpyramidal cells (Table 1). The pyramidal clusters included 113 cells in total that showed im- 
Table 2. Clusters of pyramidal neurons

\begin{tabular}{lcl} 
& Clusters & $\begin{array}{l}\text { Cells/ } \\
\text { cluster }\end{array}$ \\
\hline (A) Glu+/Asp+/GABA- & 2 & $2-4$ \\
(B) Glu+/Asp $\pm / G A B A-$ & 15 & $3-23$ \\
(C) Asp+/Glu $\pm / G A B A-$ & 5 & $2-6$ \\
(D) Glu+/Asp \pm+ glia & 1 & 58
\end{tabular}

Clusters containing pyramidal neurons generated by retrovirus injections at different embryonic ages are pooled here. They have been subdivided according to the amino acid immunoreactivity that they expressed. Four groups could be recognized: a group where all neurons were homogeneously immunoreactive for both Asp and Glu (A); a group in which all neurons were immunoreactive for Glu, but only a few were immunoreactive for Asp (B); a group where all neurons were immunoreactive for Asp, but only a few were immunoreactive for Glu (C); and a single cluster of 20 pyramidal neurons, homogeneously immunoreactive for Glu, and 38 astrocytes as assessed by electron microscopy (D). None of these cells was immunoreactive for GABA. The phenotypes of all neurons was confirmed by ultrastructural analysis.

munoreactivity for Glu, Asp, or both. Immunoreactivity for Glu occurred in $95 \%$ of these cells, whereas pyramidal neurons immunoreactive for Asp only were 7 of 113 . The Glu-immunonegative pyramidal neurons were found in five clusters containing cells all immunoreactive for Asp (Table 2). The nonpyramidal clusters included 62 neurons that were all immunoreactive for GABA (or for GABA and Asp), except for a group of three neurons that did not show immunoreactivity for any of these amino acids (see Fig. 5). The group of pyramidal clusters included one mixed cluster composed of pyramidal neurons and astrocytes. In this case, the pyramidal neurons were dispersed throughout layers II-VI, while the astrocytes were tightly clustered in layer IV.

Clusters of pyramidal neurons included 2-23 neurons (Table 2 ). In semithin sections, the $\beta$-gal reaction product appeared as a blue ring outlining the nuclear envelope, often accompanied by two or more spots of blue reaction product located at the base of the apical and basal dendrites (Figs. $1 A, B ; 2 D ; 3 B$ ). However, other pyramidal cells showed more abundant reaction product associated with the nucleoplasm and cytoplasm (Figs. $2 A, 3 A$ ). At the electron microscopic level, the reaction product was identified both in the nucleus and cytoplasm (Fig. $2 B$ ). In the nucleus it often appeared as "puffs" along the nuclear envelope (Fig. $2 B$, arrows) and only occasionally within the nucleoplasm. Outside the nucleus, the $\beta$-gal reaction product usually appeared as distinct patches associated with a few organelles, such as granular endoplasmic reticulum and Golgi complex and
Table 3. Clusters of nonpyramidal neurons

\begin{tabular}{lll} 
& Clusters & $\begin{array}{l}\text { Cells/ } \\
\text { cluster }\end{array}$ \\
\hline (A) GABA+/GLU-/ASP \pm & 23 & $2-4$ \\
(B) GABA-/GLU-/ASP- & 1 & 3
\end{tabular}

Clusters containing nonpyramidal neurons generated by retrovirus injections at different embryonic ages are pooled here. Only two groups could be recognized: a group including 23 of 24 clusters was composed of GABA-immunoreactive neurons -less than $5 \%$ of these nonpyramidal neurons, all from different clusters, were immunoreactive for Asp and none was immunoreactive for Glu (A); a single cluster of three neurons that were not immunoreactive for any of the amino acid neurotransmitters tested (B). However, all these cells displayed ultrastructural features typical of nonpyramidal neurons, including the presence of asymmetrical axosomatic synapses.

mitochondria, and it was rarely dispersed throughout the cytoplasm. In all cases, the axosomatic synapses observed were of the symmetrical variety (Fig. $2 C$ ). Figure $2 A$ shows a cluster of six pyramidal neurons in the motor cortex of a brain injected with retrovirus at E16. The camera lucida drawings of these neurons showed that the processes were stained to a variable extent, which made it difficult to determine the phenotype of every one of these cells using the light microscope. However, electron microscopical examination showed that all cells displayed features typical of pyramidal neurons (Fig. $2 B$ ), including the presence of axosomatic synapses of the symmetrical type only (Fig. 2C). All six neurons were immunoreactive for Glu (Fig. $1 C$ ), two were immunoreactive for Asp (Fig. $2 E$ ), but none was immunoreactive for GABA (Figs. $1 D, 2 F$ ). Figure $3 A$ shows a cluster of eight pyramidal neurons in the visual cortex of a rat injected with retrovirus at E14. All these cells were immunoreactive for Glu (Fig. 3C), but not for GABA (Fig. 3D).

Clusters of nonpyramidal neurons comprised two or three cells (only once four cells) and were confined to one or two layers (Table 1, Fig. 4A). Neurons within these clusters were immunoreactive for GABA (Figs. $1 F, H ; 4 E$ ), and very rarely $(<5 \%)$ for Asp, but they were never immunoreactive for Glu (Table 3, Fig. $4 F$ ). The $\beta$-gal reaction product usually filled the cytoplasm and covered the nucleus of labeled nonpyramidal neurons (Figs. $1 E, G ; 4 D)$. Characteristic ultrastructural features of nonpyramidal neurons (indented nucleus, rich complement of cytoplasmic organelles, presence of both symmetrical and asymmetrical axosomatic synapses) (Fig. $4 B, C$ ) were displayed by all GABA-immunoreactive neurons. Also, three neurons in a cluster (Fig. $5 A$ ) that did not react for any of the neurotransmitters tested, had features typical of nonpyramidal neurons (Fig. $5 B$ ).

Figure 1. Light micrographs of unstained and immunostained semithin sections taken through $\beta$-gal+ neurons in the cerebral cortex of rats injected with retrovirus at E16. $A-D$, Pyramidal neuron. This neuron (arrow) was part of the cluster of clonally related pyramidal neurons shown in Figure 2 (cell $b$ ). The pattern of $\beta$-gal staining was typical of many pyramidal neurons $(A)$. It consisted in a ring of blue reaction product outlining the nucleus and spots of reaction product at the origin of two of the dendrites. The same neuron is shown at lower magnification in $B$. After immunostaining, this neuron revealed immunoreactivity for Glu $(C)$, but not for GABA $(D)$. The same neighboring neurons $(1-6)$ are shown in the three consecutive sections. $E-H$, Two clonally related nonpyramidal neurons. The $\beta$-gal staining is similarly very intense in these cells $(E$, $G$ ) and fills both their cytoplasm and nucleus. These neurons (arrows) were immunoreactive for GABA $(F, H)$, but not for Glu (not shown). Asterisks indicate the same blood vessels in adjacent sections. Magnification: $A, E-H, 1340 \times ; B-D, 600 \times$

Figure 2. A cluster of six clonally related $\beta$-gal + pyramidal neurons in the motor cortex of a rat injected with retrovirus at E16 $(A)$. Cell morphology is poorly defined for most of these neurons, and particularly for cells $b$, $e$, and $f$. An electron micrograph of cell $f$ is shown in $B$. The $\beta$-gal reaction product is associated with the nuclear envelope (arrows) and with a number of cytoplasmic organelles (asterisks). All axosomatic synapses encountered were of the symmetrical variety, a feature of all cortical pyramidal neurons, one of which is contained in the boxed area and shown at higher magnification in $C$. All neurons of this cluster were immunoreactive for Glu and only two of them were also immunoreactive for Asp (cells $b$ and $e$ ). $D-F$ show cell $e$ (arrow) in an unstained semithin section showing the disposition of $\beta$-gal reaction product $(D)$, after immunostaining for Asp (positive; $E$ ), and after immunostaining for GABA (negative; $F$ ). The same neighboring neurons (I-3) are shown in the three sections. Asterisks mark the same blood vessel. Magnification: $B, 10,000 \times ; C, 50,000 \times ; D-F, 640 \times$. 

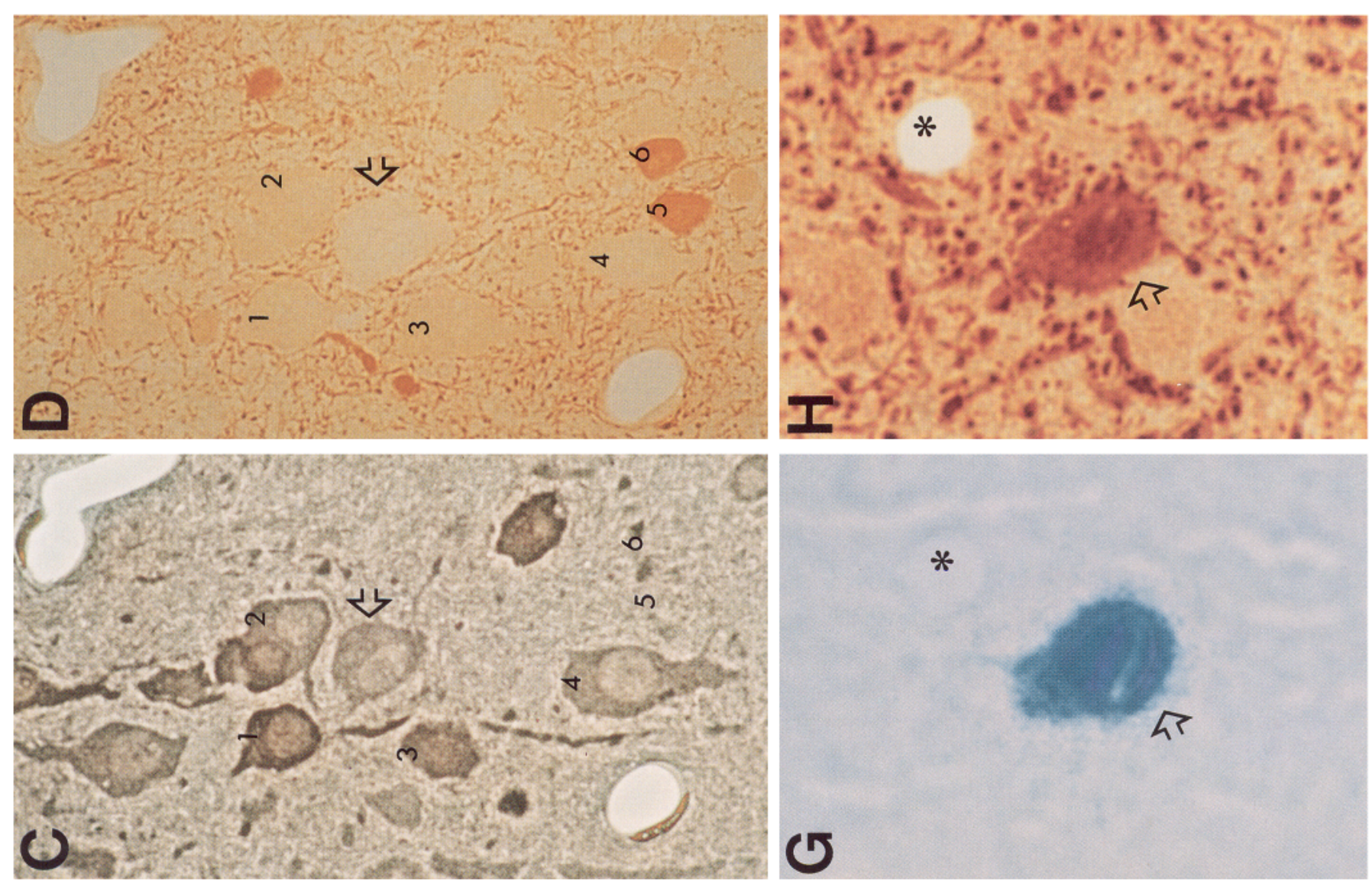

\section{ज}
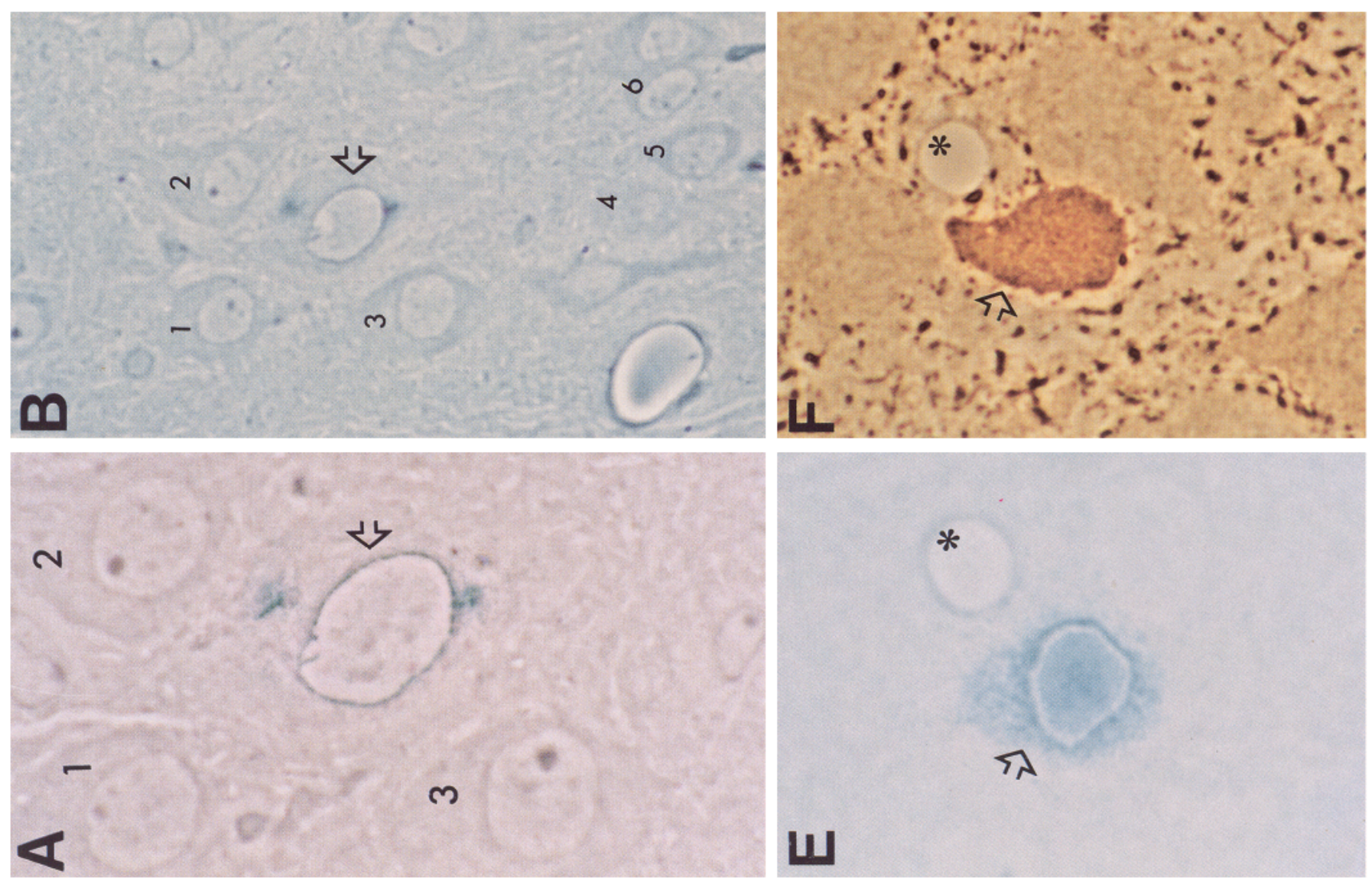

*

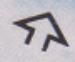

Ш 

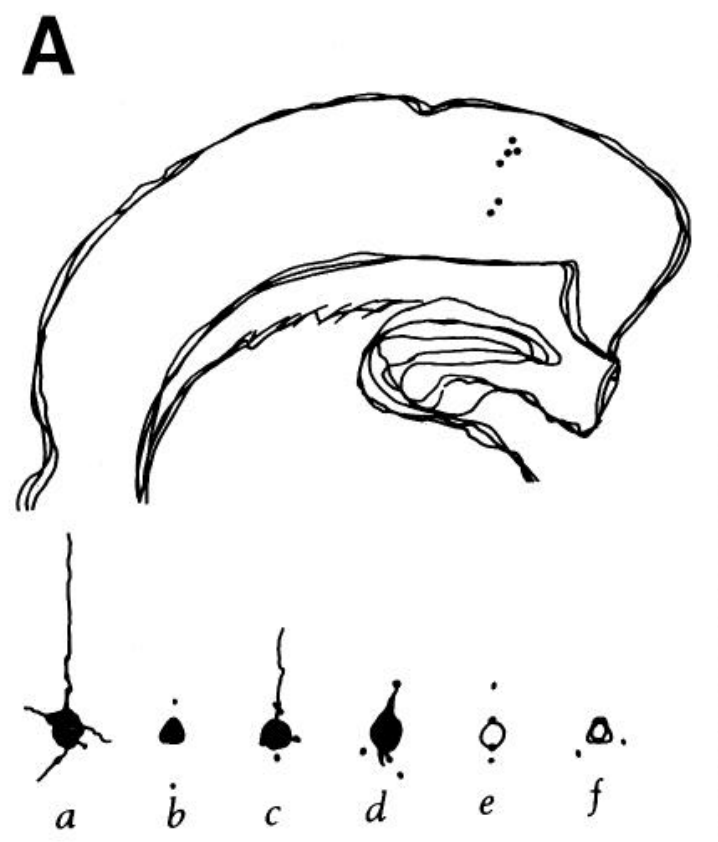

$B .6 \% 100010$

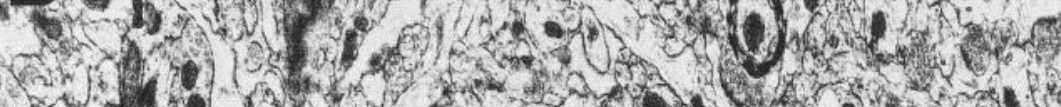

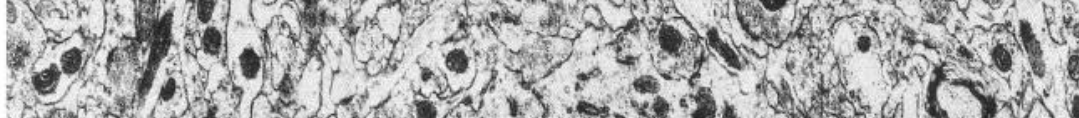

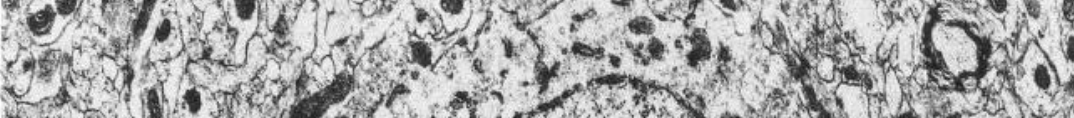

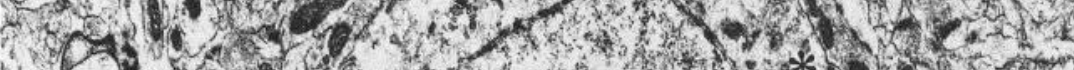

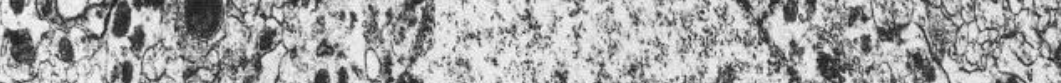

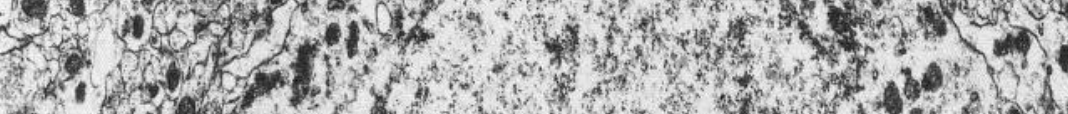

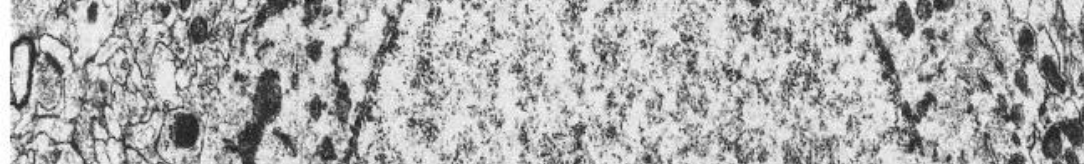

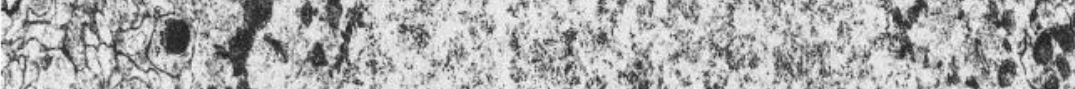

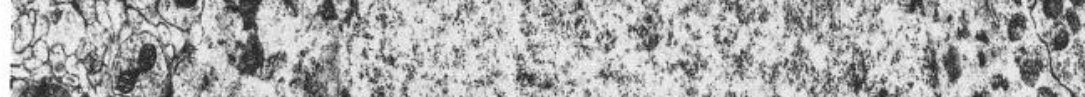

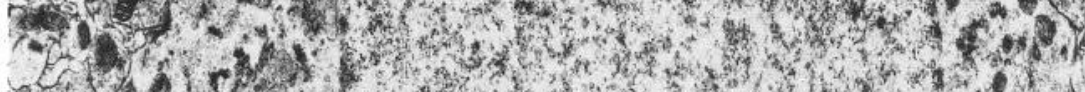

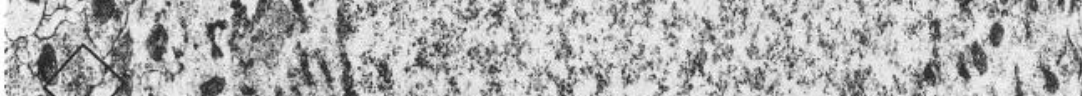

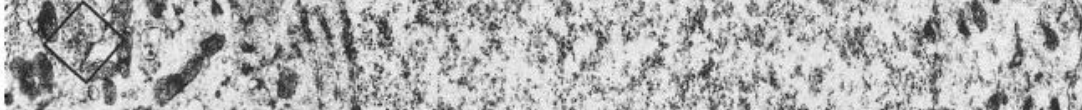

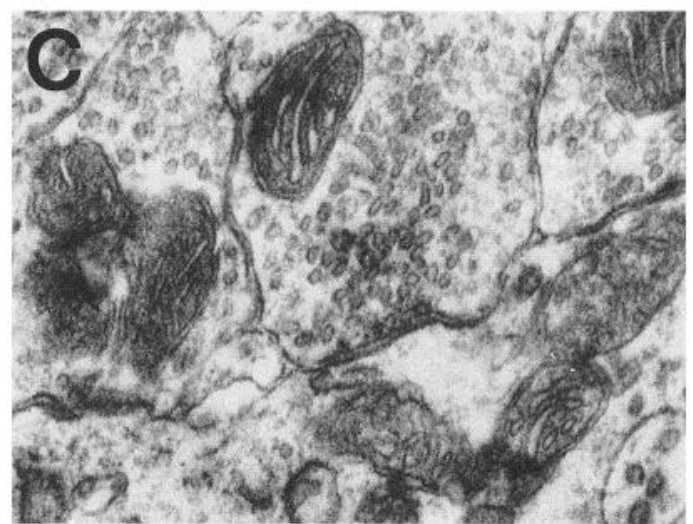
6.

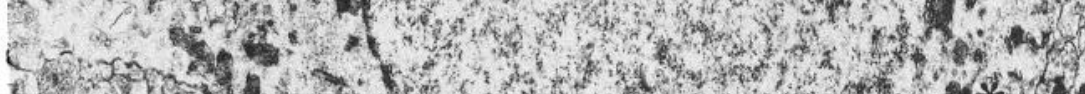

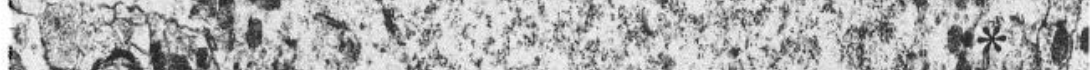

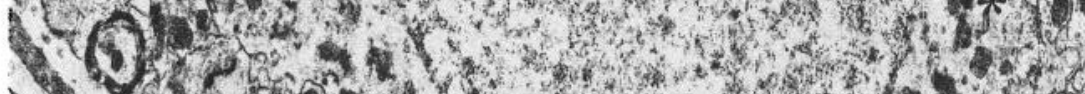

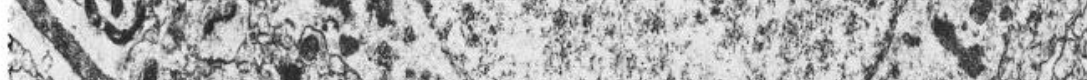

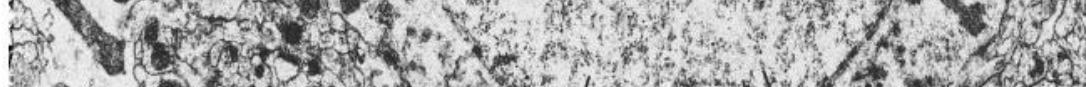

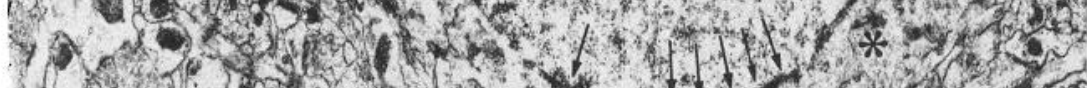

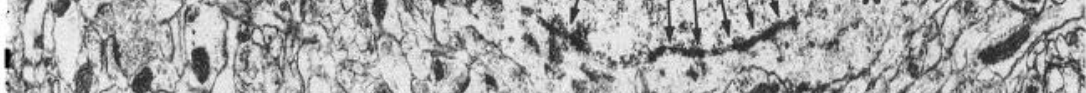

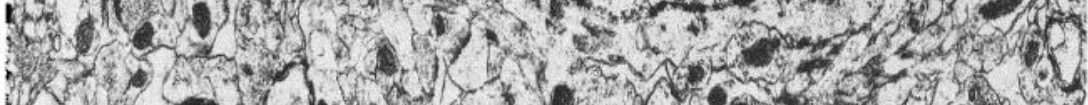
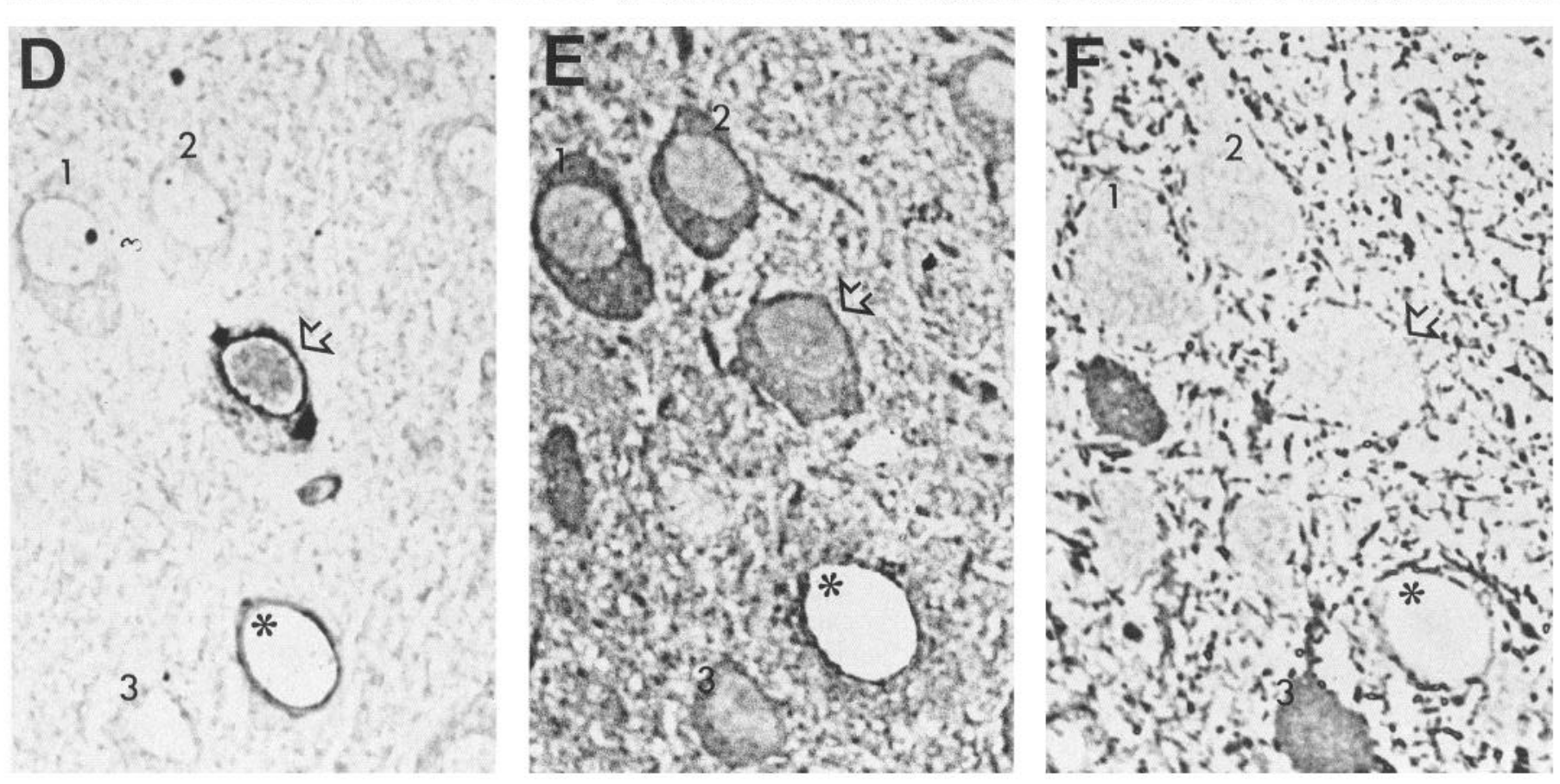

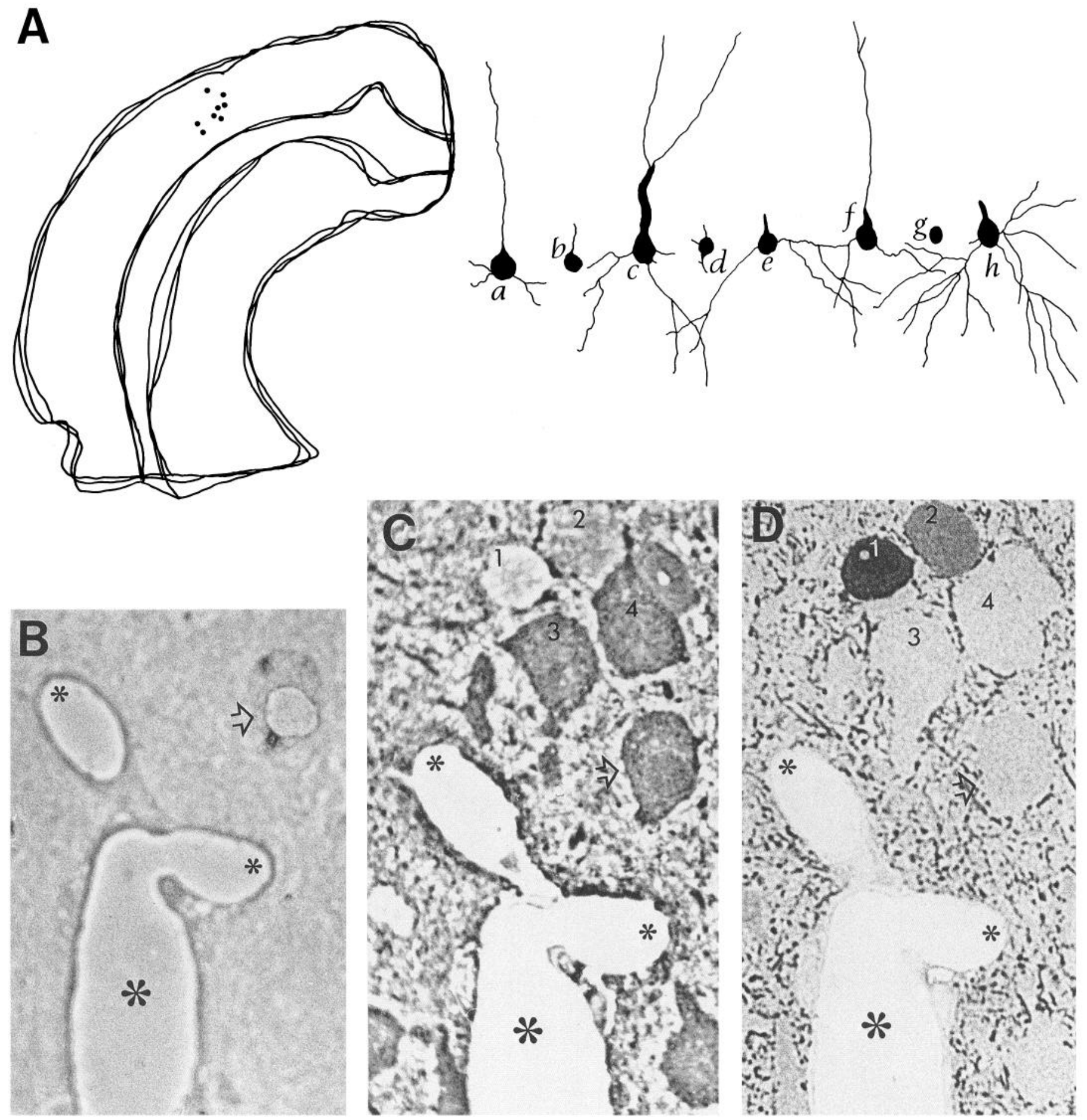

Figure 3. A cluster of eight clonally related $\beta$-gal + pyramidal neurons in the visual cortex of a rat injected with retrovirus at E14 $(A)$. Four of these cells displayed morphological features typical of pyramidal neurons after $\beta$-gal histochemistry, but the other four were difficult to classify without further staining. $B-D$ show cell $b$ (arrow) in an unstained semithin section $(B)$, after immunostaining for Glu (positive; $C$ ), and after immunostaining for GABA (negative; $D$ ). The same neighboring neurons $(1-4)$ are shown in different sections. A large blood vessel and its branches are marked by asterisks. Magnification $(B-D), 640 \times$.

Figure 4. A cluster of two $\beta$-gal + nonpyramidal neurons in the visual cortex of a rat injected with retrovirus at E15 $(A)$. One cell $(a)$ was readily identified as a nonpyramidal neuron, while it was not possible to determine the identity of the other $(b)$ because of lack of process staining. An electron micrograph of cell $b$ is shown in $B$. The $\beta$-gal reaction product is associated with the nuclear envelope (arrows) and various cytoplasmic organelles (asterisks). In this and in other sections this cell shows features typical of cortical nonpyramidal neurons, that is, an indented nucleus and a number of both symmetrical and asymmetrical synapses. One of the latter is contained in the boxed area and shown at higher magnification in $C . D-F$ show cell $b$ (arrow) in an unstained semithin section $(D)$, after GABA immunostaining (positive; $E$ ), and after Glu immunostaining (negative; $F$ ). The same neighboring neurons $(1-3)$ are shown in three consecutive sections; asterisks mark the same blood vessels. Magnification: $B, 11,500 \times ; C, 50,000 \times ; D-F, 640 \times$. 

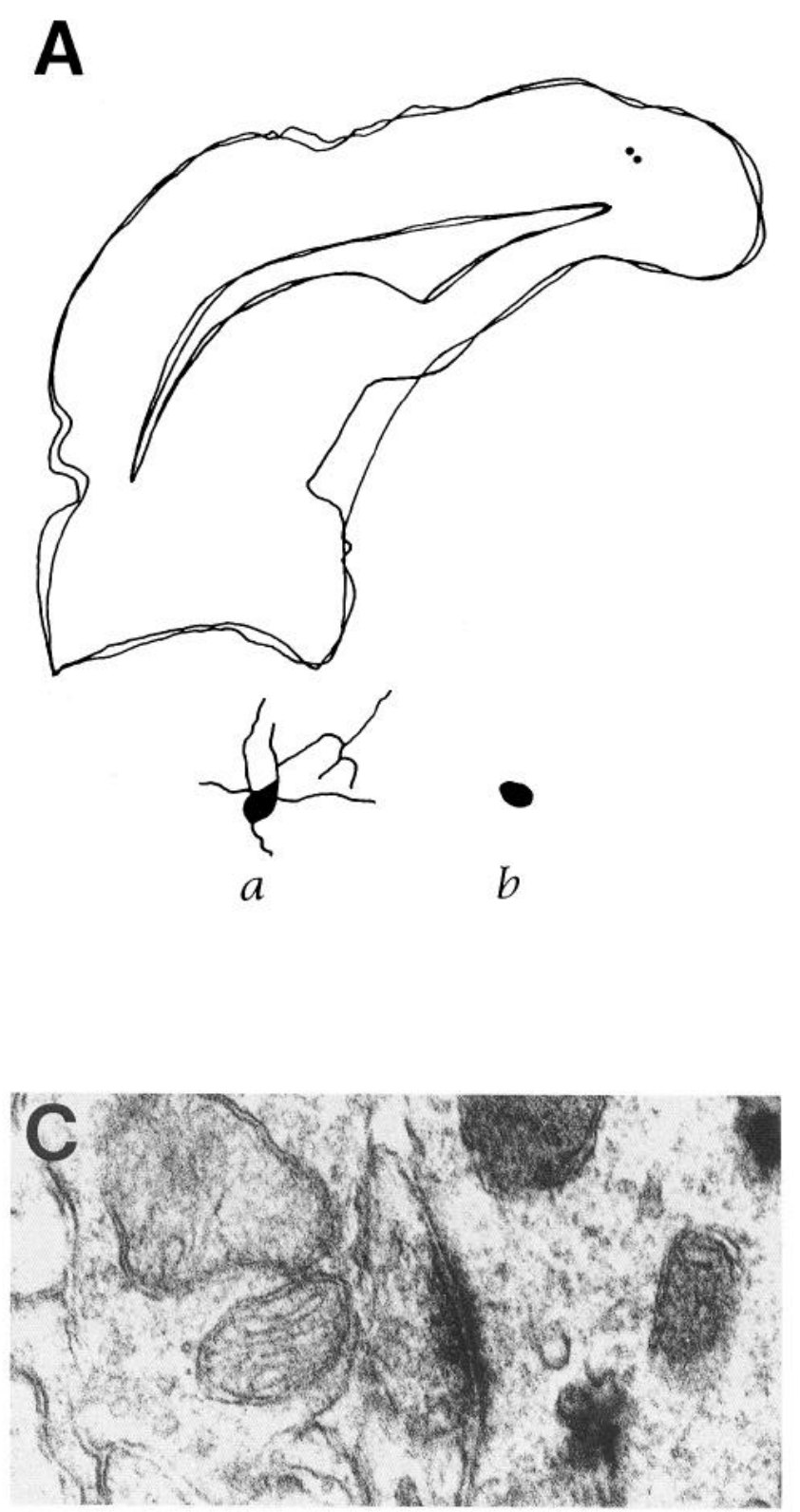

B. - 10.12 .02

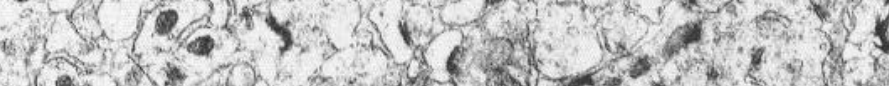

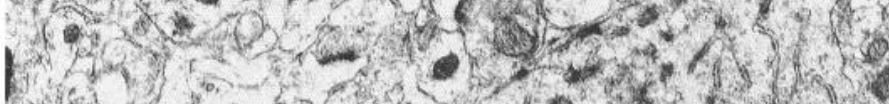

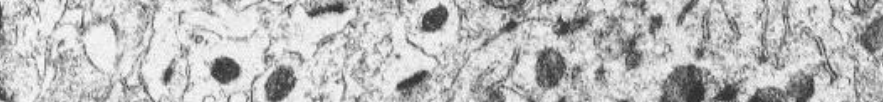

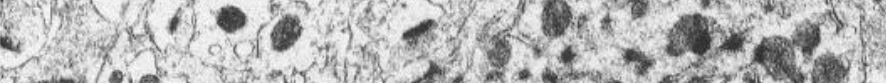

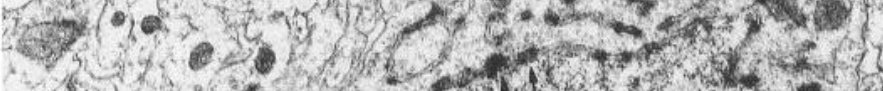

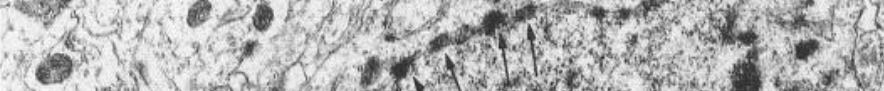

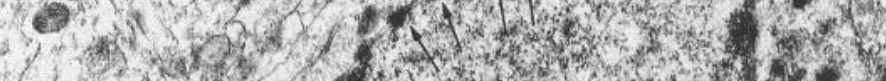

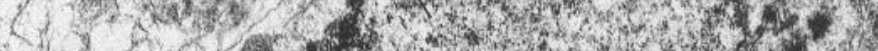

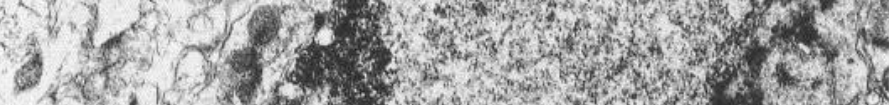

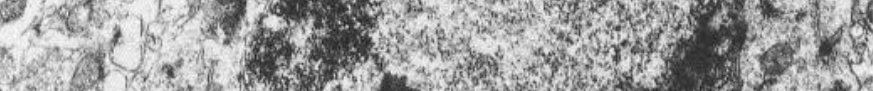

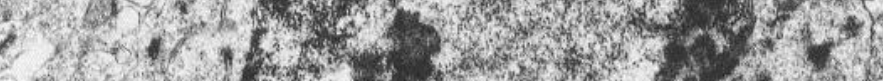

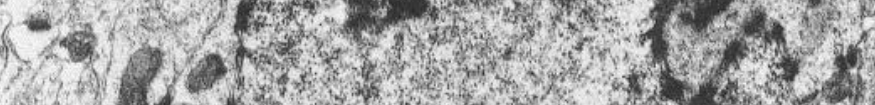

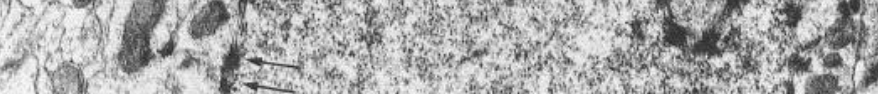

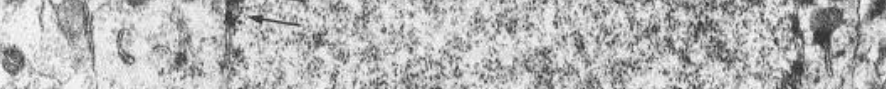

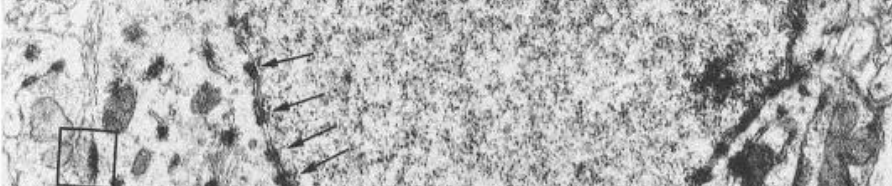

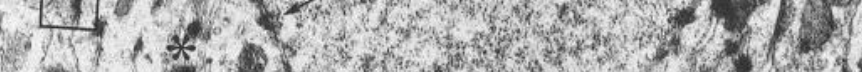

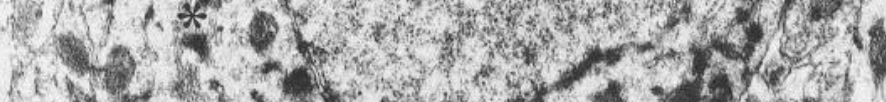

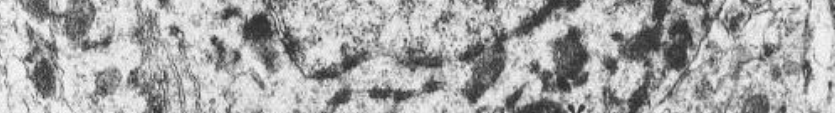

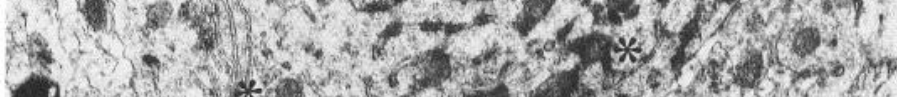

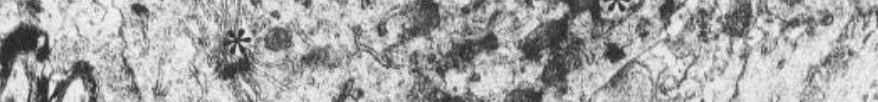

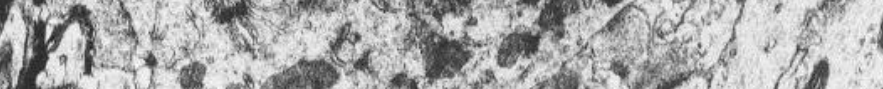
$6 x^{2}-43$
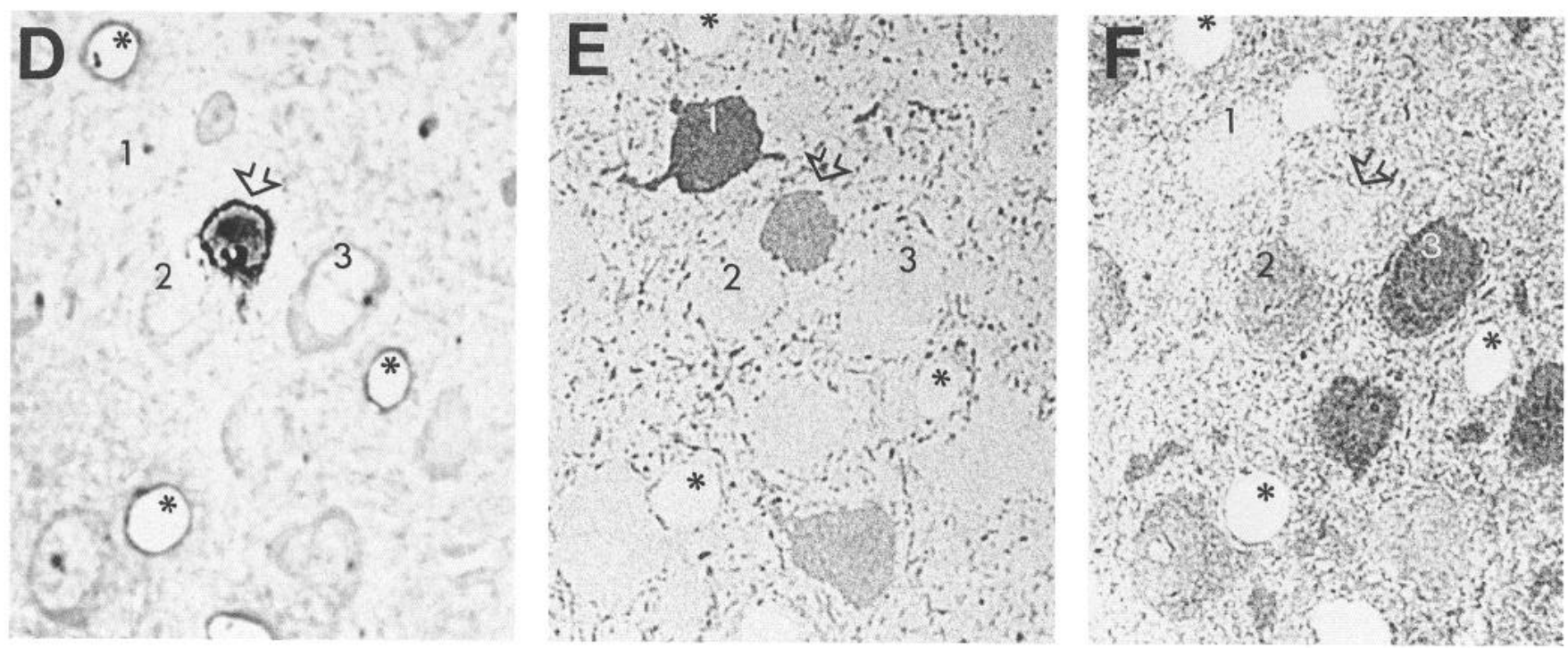

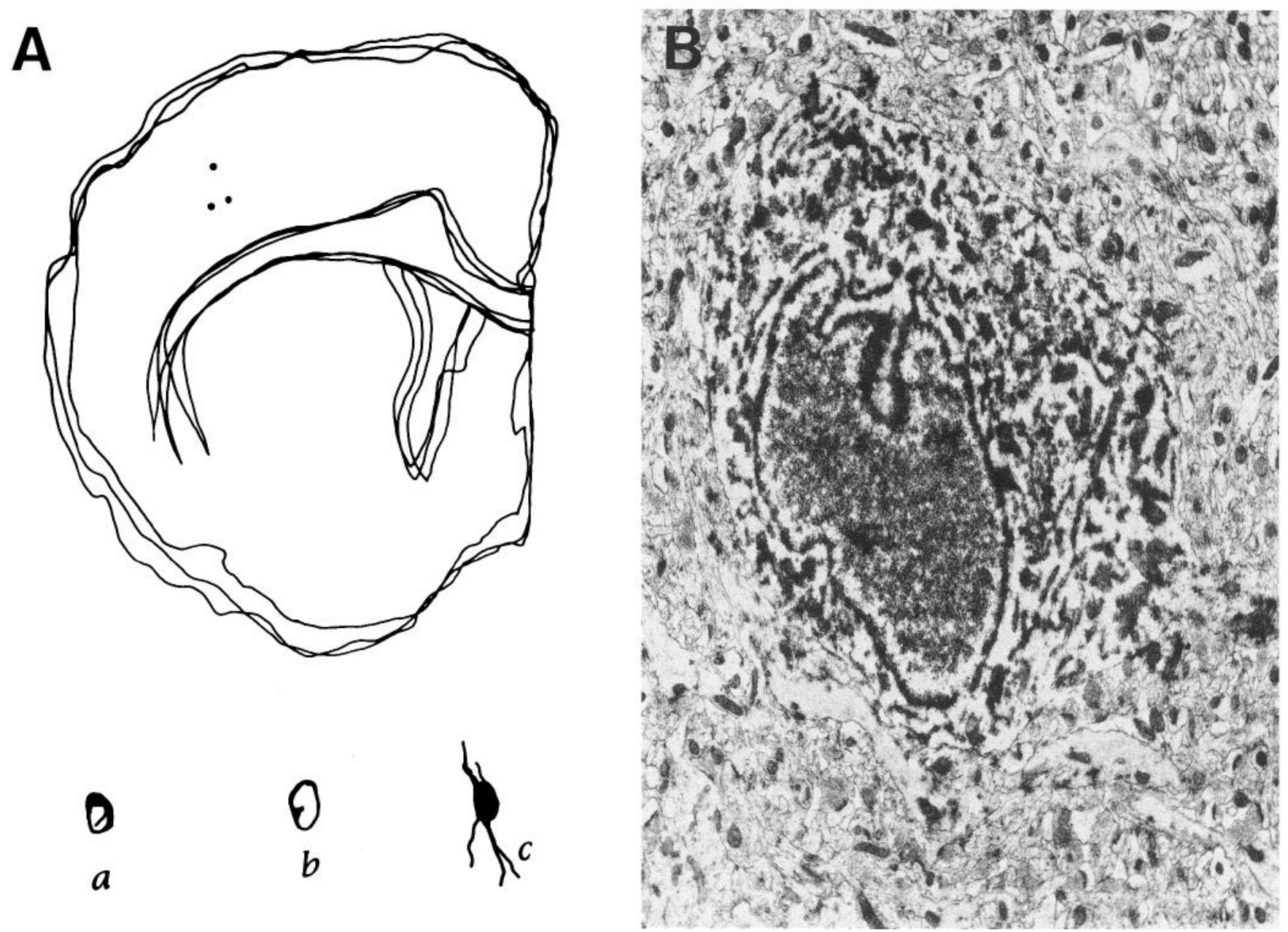

Figure 5. A cluster of three $\beta$-gal+ nonpyramidal neurons in the somatosensory cortex of a rat injected with retrovirus at E16 $(A)$. All three neurons displayed ultrastructural features typical of nonpyramidal neurons, including an indented nucleus, rich complement of cytoplasmic organelles, and both asymmetrical and symmetrical axosomatic synapses. $B$ shows an electron micrograph of cell $c$ that is heavily stained after $\beta$-gal histochemistry, a feature of many nonpyramidal neurons. These cells were not immunoreactive for GABA, Glu, or Asp. Magnification $(B), 8700 \times$.

\section{Parvalbumin, calbindin, and calretinin immunoreactivity in clonally related nonpyramidal neurons}

The distribution of the calcium-binding proteins Parv, Calb, and $\mathrm{Cr}$ was investigated in 16 of 24 clusters of nonpyramidal neurons. In general, immunoreactivity for Parv and Calb occurred in a limited number of GABA-immunoreactive neurons, and $\mathrm{Cr}$-immunoreactive neurons were less frequent. This fact reduced the chances that $\beta$-gal+ nonpyramidal neurons could express one or more of these immunoreactivities. However, in these clusters 15 of $36 \beta$-gal + nonpyramidal neurons were immunoreactive for Parv, 10 of 36 were immunoreactive for Calb, and 9 of 36 were immunoreactive for $\mathrm{Cr}$. Despite the reasonable number of $\beta$-gal + neurons also immunoreactive for one or the other calcium-binding proteins, nonpyramidal neurons were homogeneously immunoreactive for Parv in only four clusters; a single cluster of two neurons was immunoreactive for $\mathrm{Cr}$, and no cluster contained neurons homogeneously immunoreactive for Calb. Examples of this inhomogeneity are given in Figures 6 and 7, where adjacent semithin sections of four nonpyramidal neurons, belonging to two different clusters, have been processed to reveal immunoreactivity for all three calcium-binding proteins.

Coexistence among calcium-binding proteins occurred in few $\beta$-gal + cells, the most frequent coexistence being that of Parv and $\mathrm{Cr}$ (in 3 cells of 36 ); Calb and Cr immunoreactivity occurred in the same $\beta$-gal+ cell only twice, and Parv and Calb immunoreactivity coexisted in the same $\beta$-gal+ cell only once.

Figure 6. Light micrographs of semithin sections taken through two clonally related $\beta$-gal+ nonpyramidal neurons in the somatosensory cortex of a rat injected with retrovirus at E14. $A-D$ show one of the two cells (open arrow) in an unstained semithin section $(A)$, after GABA immunostaining (positive; $B$ ), after immunostaining for Parv (positive; $C$ ), and after immunostaining for $\mathrm{Cr}$ (negative; $D$ ). The same neighboring neurons $(l, 2)$ are shown in the four sections. Asterisks mark the same blood vessels, and small arrows in $D$ point to $C r$-immunoreactive boutons. $E-H$ show the other cell (arrow) in an unstained semithin section $(E)$, after immmunostaining for GABA (positive; $F$ ), after immunostaining for Parv (positive; $G$ ), and after immunostaining for $\mathrm{Cr}$ (positive; $H$ ). The same neighboring neuron $(1)$ is shown in the four sections. Asterisks mark the same blood vessels. Note that the two cells of this cluster were homogeneously immunoreactive for GABA and Parv, but not for Cr. Magnification $(A-H)$, $640 \times$. 

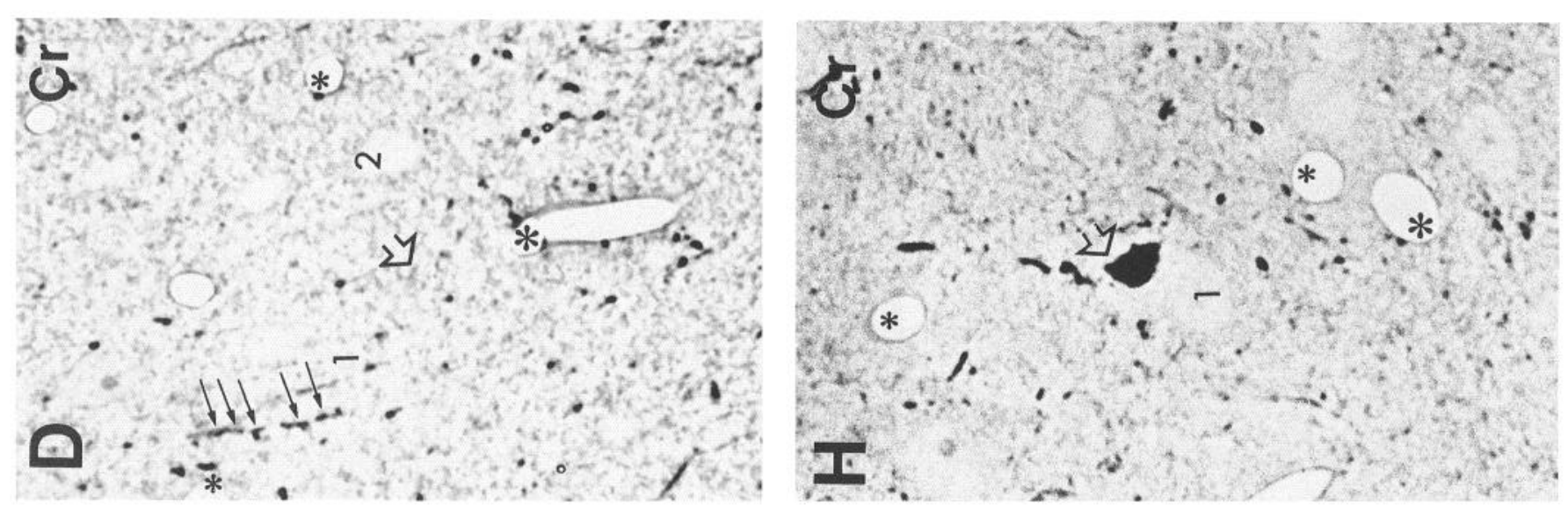

and

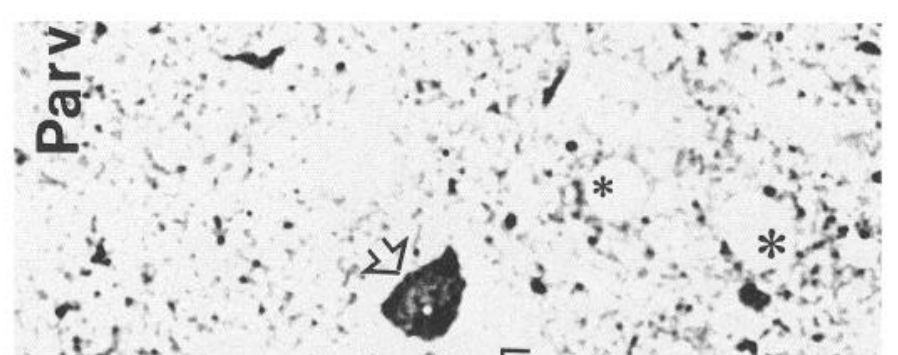

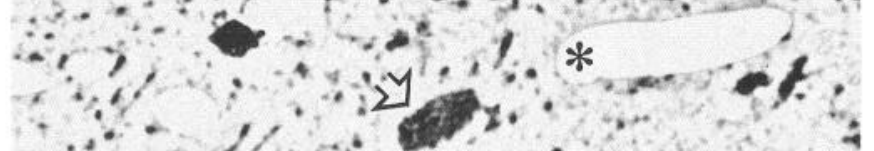

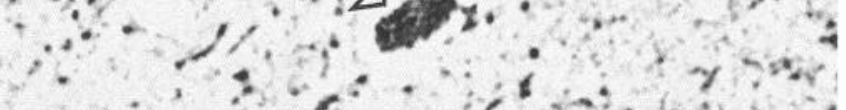

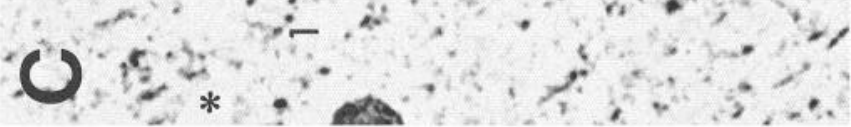

(5)

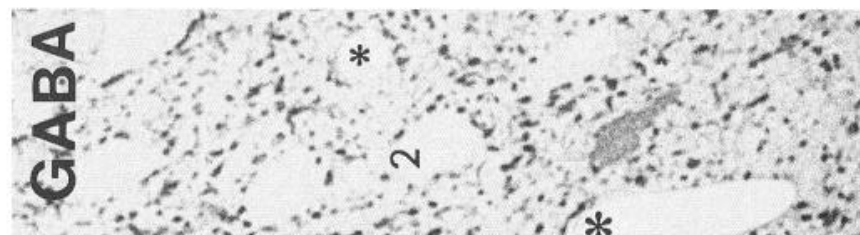

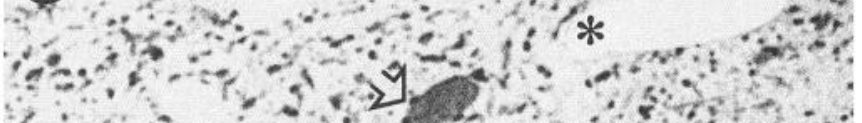
a il

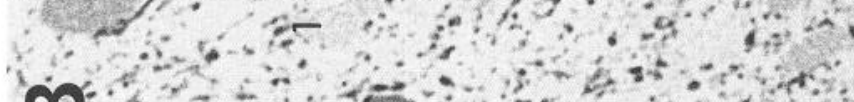

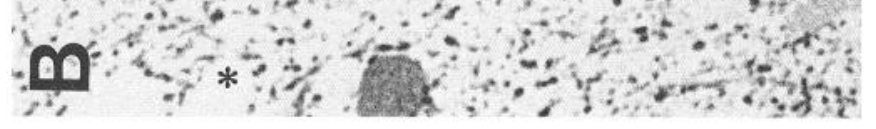

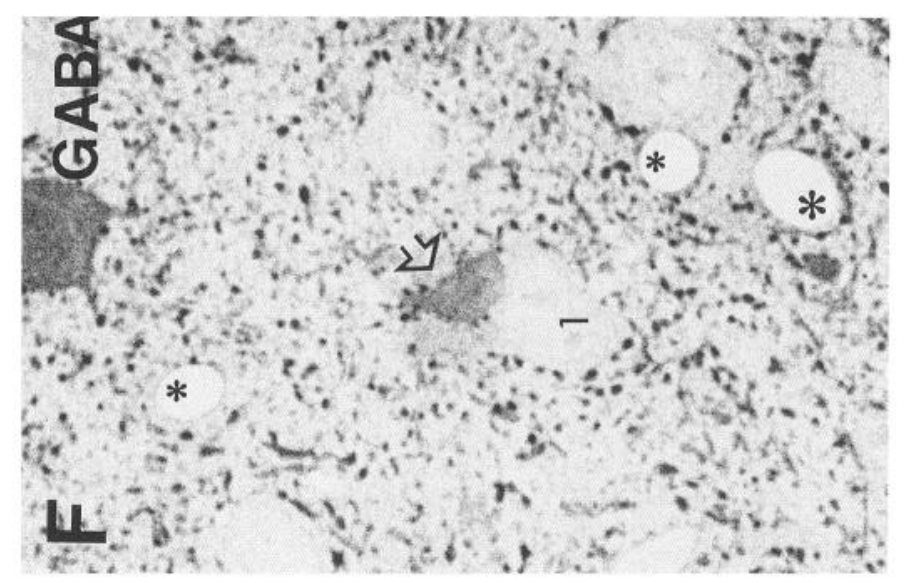
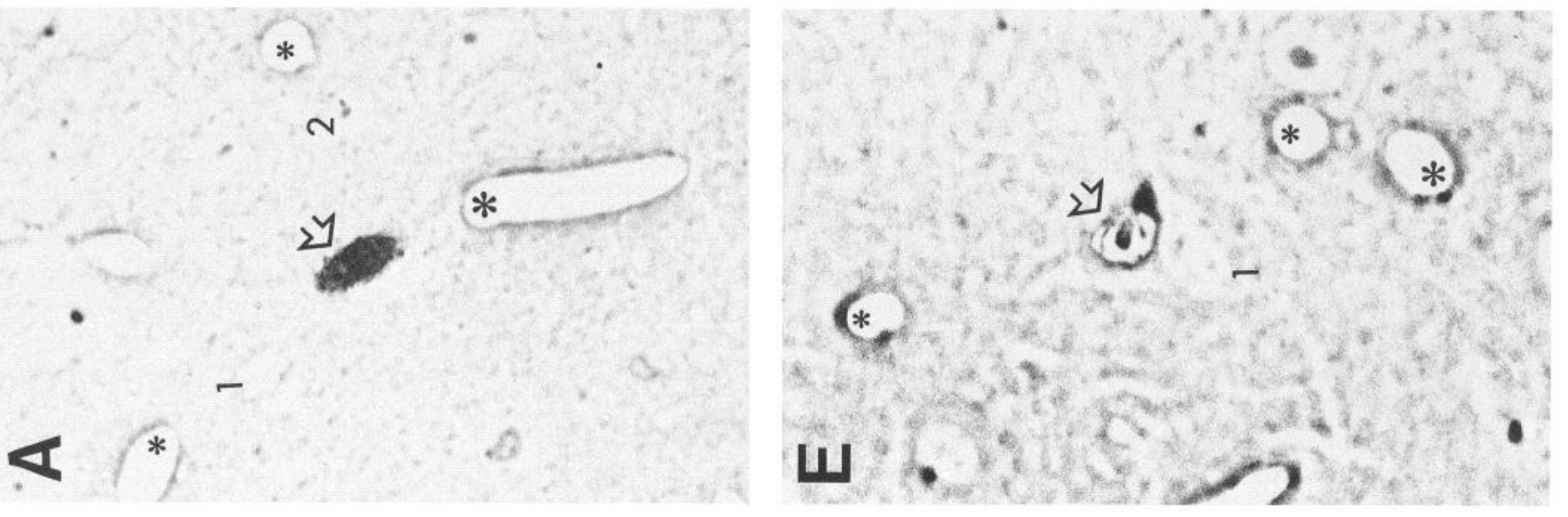

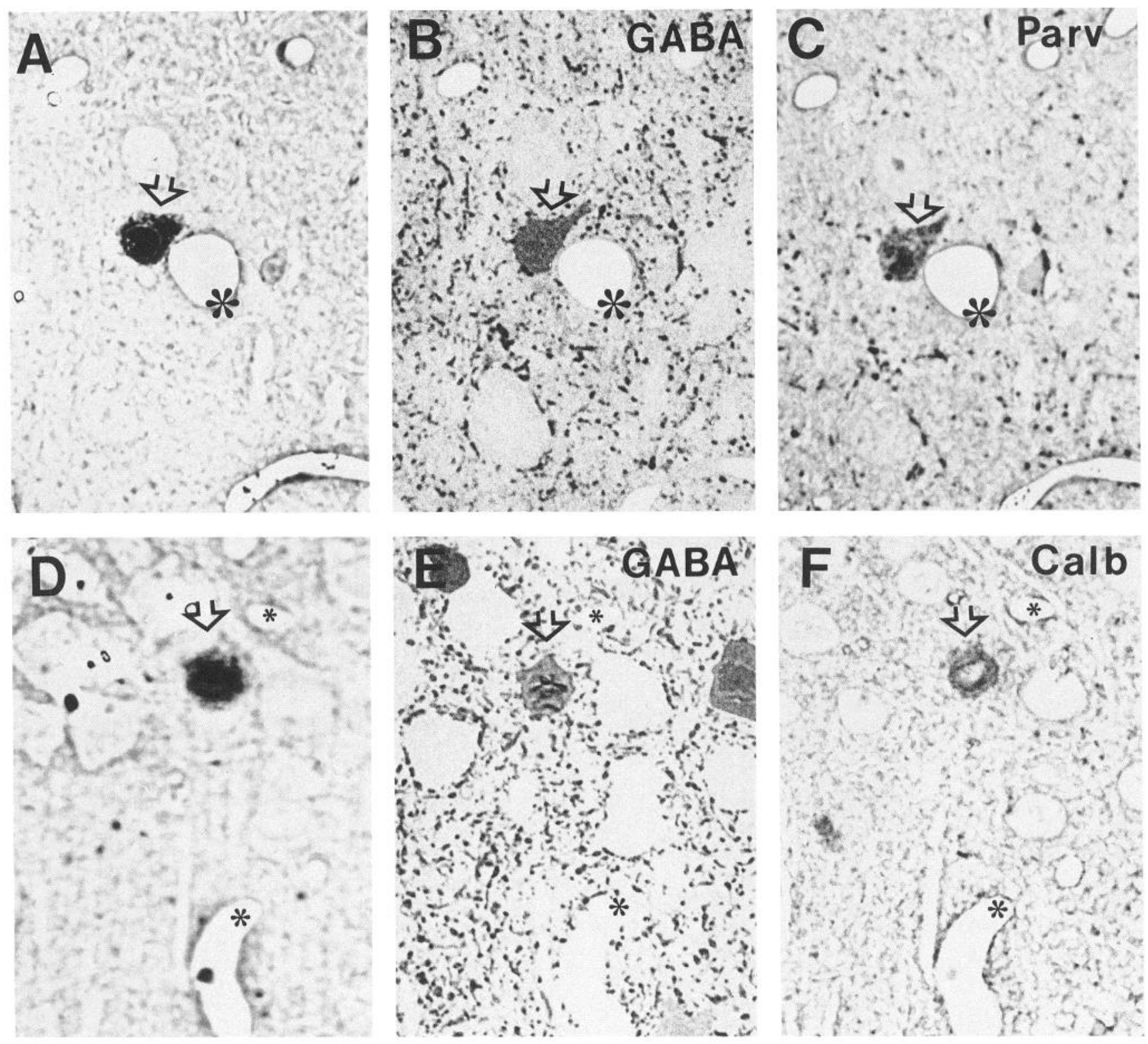

Figure 7. Light micrographs of semithin sections cut through two $\beta$-gal+ cells, which were part of a three cell cluster of nonpyramidal neurons. The cluster was located in the temporal cortex of a rat injected at E15. $A-C$ show one of the two cells (arrow) in an unstained semithin section $(A)$, after immunostaining for GABA (positive; $B$ ), and after immunostaining for Parv (positive; $C$ ). $D-F$ show the other cell (arrow) in an unstained semithin section $(D)$, after immunostaining for GABA (positive; $E$ ), and after immunostaining for Calb (positive; $F$ ). Asterisks mark the same blood vessels in consecutive sections. Note that the first cell was not immunoreactive for Calb and the other cell was not immunoreactive for Parv. The third cell of this cluster was not immunoreactive for any of the calcium-binding proteins tested. Magnification $(A-F), 640 \times$.

\section{Discussion}

The present findings, obtained using immunohistochemistry for the classical amino acid neurotransmitters on BAG-infected, $\beta$-gal + neurons, confirmed the homogeneity of clonal relatives in the cerebral cortex of the adult rat (Parnavelas et al., 1991; Luskin et al., 1993) and extended the number of clusters of clonally related cells subjected to reliable classification. Our findings may be summarized as follows. (1) Neuronal clusters are homogeneous for Glu or GABA immunoreactivity in brains injected from E14 to E19; thus, the period during which progenitor cells committed to produce only one cell phenotype are found in the ventricular zone is extended to an earlier stage than previously documented. (2) Different calcium-binding proteins may be present in clonally related cortical nonpyramidal neurons. The pattern of expression of these proteins is therefore independent of lineage. (3) Size and laminar distribution of clusters of clonally related neurons differ substantially for the two cortical cell types; such differences were more evident for early (E14) injections. However, the interpretation of these findings is based on the assumption that the clusters of $\beta$-gal + cells, observed in our experiments, only include clonal relatives.

\section{Assignment of clonal boundaries}

It is mainly through statistical analysis that we can claim that the clustered $\beta$-gal + cells considered in this study are part of 
the same clone. Two points were taken into consideration before such analysis was carried out: (1) the rare occurrence of infection of two adjacent progenitors (Fields-Berry et al., 1992) and (2) the randomness of the widespread dispersion (Walsh and Cepko, 1992). Thus, we selected only brains with a low number of infective events (see Grove et al., 1992, 1993) and used statistical analysis and computer simulation to calculate the probability that random dispersion can cause aggregation of cells originating from different progenitors. These analyses were confirmed by a number of empirical observations, namely, (1) clones of glial cells that are known to remain strictly clustered in the cortex (Price and Thurlow, 1988; Price et al., 1992; Walsh and Cepko, 1992; Grove et al., 1993; Luskin et al., 1993) were never invaded by "randomly dispersed" neurons in our study - the only mixed cluster that we observed most likely represented a polyclone because of the large number of both types of cells; (2) the use of two different retroviruses in the chick optic tectum (Gray et al., 1988), where lateral migration has recently been demonstrated (Gray and Sanes, 1992; Martinez et al., 1992), did not give rise to mixed clones (i.e., clones containing progeny of cells infected by the two retroviruses); and (3) while the dramatic growth of the cerebral cortex during development may represent one of the main determinants of the widespread dispersion observed by Walsh and Cepko (1992), it also means that the probability of superimposition of clones (at least in lightly infected brains) is very low.

All studies carried out on the cerebral cortex with recombinant retrovirus have reported the presence of isolated "single" $\beta$-gal+ cells. Such cells may give an indication of the proportion of cells that escape from their clonal relatives, especially in lightly infected brains. In these brains, the chance that randomly migrating $\beta$-gal + cells end up in close proximity to a cluster of other $\beta$-gal + cells is very limited (Grove et al., 1992; present results). Thus, a proportion of these isolated $\beta$-gal + cells probably represent those cells that escaped from their relatives. However, some isolated $\beta$-gal + cells may represent the remains of a cluster whose siblings died or failed to express the reporter gene, or the very rare "one-cell clones" (Walsh and Cepko, 1988; Halliday and Cepko, 1992; M. C. Mione, unpublished observation). In the studies of Price and colleagues (Grove et al., 1992) and Cepko and colleagues (Austin and Cepko, 1990; Walsh and Cepko, 1992), "single-cell clones" represent approximately half of the total number of clones, while in the present study they were approximately $65 \%$. We carried out some experiments to clarify the origin of these "single" $\beta$-gal + cells. We evaluated the percentage (over the total number of clones) of single $\beta$-gal + cells in the brains of 25 rats injected with recombinant retrovirus at E16 and examined at different ages (E19, P0, P7, P14, P28 and older). In order to verify that single $\beta$-gal + cells observed in $100-\mu \mathrm{m}$-thick Vibrotome sections of brains harvested at E19 and P0 were not aggregates of two or more cells, we cut 0.5 $\mu \mathrm{m}$-thick sections through these cells, after embedding them in Araldite (see Materials and Methods). In the majority of cases, the analysis carried out in E19 brains revealed that what appeared as single $\beta$-gal + cells in thick sections in reality were groups of two or three closely apposed $\beta$-gal + cells. At all other ages, including $\mathrm{P} 0$, the counting of single $\beta$-gal + cells in Vibrotome sections was accurate. We found that single $\beta$-gal + cells represented $9.2 \%$ of all clones at $\mathrm{E} 19,35.9 \%$ at $\mathrm{P} 0,44.6 \%$ at $\mathrm{P} 7,42 \%$ at P14, and $58 \%$ at $\mathrm{P} 28$ and in older rats. Thus, the number of "single-cell clones" originated by retrovirus injection at $\mathrm{E} 16$ is given by the single $\beta$-gal + cells already present at E19, while the additional single $\beta$-gal + cells appearing at $\mathrm{P} 0$ and later must be generated differently. The increase of the percentage of single $\beta$-gal + cells between E19 and P7 (from 9.2\% to $44.6 \%$ ) may be due to nonradial migration while the successive increase between $\mathrm{P} 7$ and adulthood (from $44.6 \%$ to $58 \%$ ) may be due to death of clonal relatives or cessation of expression of the reporter gene. Unfortunately, there are no techniques available at the present to resolve clonal boundaries in adult rats. The use of the polymerase chain reaction to distinguish different retroviral constructs in $\beta$-gal + cells (Walsh and Cepko, 1992) has recently been criticized for the experimental design (Kirkwood et al., 1992; Grove et al., 1993; Luskin et al., 1993). Serious technical difficulties in amplifying the retroviral constructs in all $\beta$-gal + cells have been reported by the authors themselves (Halliday and Cepko, 1992; Walsh and Cepko, 1992, 1993).

Glu- and GABA-immunoreactive cortical neurons are phenotypically distinct cell populations since the early stages of development

From a simple biochemical point of view, nonpyramidal neurons differ from pyramidal neurons in their ability to convert glutamate into GABA, which is due to the presence of the enzyme glutamic acid decarboxylase. The theories that consider nonpyramidal neurons as an evolution of some pyramidal neurons, which are largely based on morphological observations (Marin-Padilla, 1992; Vercelli et al., 1992), should not be discarded a priori. However, a wealth of data indicate that pyramidal and nonpyramidal neurons are distinct populations of postmitotic cells since their generation and, in accordance with a number of lineage studies (Parnavelas et al., 1991; Luskin et al., 1993), even before. The development of the Glu- and GABAimmunoreactive neurons in the embryonic cortex is consistent with the notion of two classes of pyramidal and nonpyramidal neurons of the adult cortex (Lauder et al., 1986; Erdö and Wolff, 1989; Van Eden et al., 1989; Blanton and Kriegstein, 1991; Cobas et al., 1991). It has been suggested that the two neurotransmitters play critical roles in development by regulating differentiation and survival of other cells (Mattson, 1988; Mattson and Kater, 1989; for review, see Redburn and Schousboe, 1987; McDonald and Johnston, 1990). Equally convincing with regard to the early distinction of these populations of neurons are the experiments of "in vitro" differentiation of CNS neuroblasts (Buse, 1990; Stichel and Müller, 1991). In these lowdensity cultures, where no serum or growth factors are added, neuroblasts stop dividing and begin to differentiate. GABAimmunoreactive neurons are found in these cultures in similar proportion as in the adult cortex. Division of isolated CNS neuroblasts from E13.5-E14.5 rat embryos, obtained in the presence of survival factors (Temple, 1989), gave rise to clones that were $80 \%$ homogeneous for only one cell type (neuron or glia). However, the neuronal clones have not been subjected to further characterization to define their phenotype.

The role of lineage in determining the phenotype of CNS neurons and the neurotransmitter(s) that they express has been substantiated in a number of studies in invertebrates. In Manduca sexta, an early ablation of the corresponding neuroblasts resulted in permanent loss of GABA-immunoreactive neurons (Witten and Truman, 1991a,b). Other examples of phenotypic commitment of neuroblasts were reported in cultures originated from Drosophila embryos (Huff et al., 1989). In these experiments, neuroblasts removed as early as the gastrula stage were 
shown to be determined for the expression of 5-HT or dopamine.

\section{Clusters of pyramidal and nonpyramidal neurons differ in number of cells and laminar location}

One of the findings of the present study was the striking difference in size between clusters of pyramidal and nonpyramidal neurons. The clusters of pyramidal neurons were largely predictable (for their size and laminar spread) in accordance with the time of injection. However, the clusters of nonpyramidal neurons were invariably composed of two or three cells (only in one case by four cells) and resided only in the layers that were being generated at the time of injection.

This difference may be due to the fact that the two cell types may be generated by different mechanisms. Either different progenitor cells generate roughly the same number of neurons, but some nonpyramidal neurons die or migrate away from the cluster, or different progenitors generate different number of cells. With regard to the first possibility, it is highly improbable that cell death or migration would always only leave two or three clonal relatives in the same or adjacent layers, and only in those layers generated at the time of injection. The second possibility implies the presence of different progenitor cells that are committed not only to generate phenotypically different progeny, but also to undergo a different number of mitotic divisions. Thus, progenitors of nonpyramidal neurons are able to divide only once, or at the most twice, to give rise to two or three postmitotic neurons, while progenitors of pyramidal neurons produce several postmitotic cells as well as several mitotically active progeny, resulting in large clusters (up to 23 cells after injections at E14). This may be achieved through a combination of symmetrical and asymmetrical divisions as hypothesized for the chick optic tectum (Gray et al., 1990) and rat striatum (Halliday and Cepko, 1992). One possible drawback of this interpretation is the origin of the progenitors of nonpyramidal neurons. While the progressive reduction of the number of cells per cluster observed in the clusters of pyramidal neurons is compatible with the cogeneration of both postmitotic neurons and dividing precursors until E20 (when the last progenitors of pyramidal ncurons probably undergo their final division), progenitors of nonpyramidal neurons do not produce other dividing cells. If this was the case, we should observe larger groups, more like the clusters of pyramidal neurons. Instead, our observations suggest that progenitors of nonpyramidal neurons give rise only to two or three postmitotic neurons, in one or two rounds of divisions. The possibility that progenitors of nonpyramidal neurons represent a "dormant" population of preterminal precursors, largely mitotically quiescent, with a few undergoing mitosis from time to time can be discarded on the basis of two reports (Waechter and Jaensch, 1972; Takahashi et al., 1993) showing that the labeling indices (mitotically active population over whole cell population) of the murine ventricular zone at E14.5 are close to 1.0. However, it is possible that progenitors of nonpyramidal neurons originate from stem cells that also give rise to progenitors of other cell types. A common progenitor for different cell types of the cerebral cortex is likely to exist early in development. We propose that such progenitors coexist in the ventricular zone with the overwhelming population of committed progenitors until at least E17 in the rat. The presence of such multipotent progenitors in the rat ventricular zone could assure the continuous production of committed nonpyramidal progenitor cells.

\section{Models of cell lineage compatible with these observations}

We feel it is important to compare the results of two main techniques used to study cortical development, that is, the retrovirus-mediated gene transfer and ${ }^{3} \mathrm{H}$-thymidine autoradiography. The latter method marks the two progeny of every dividing cell, regardless of their location, while the reporter gene of the retroviral vectors is incorporated only in one of the daughters of an infected cell adjacent to the ventricular wall as it undergoes mitotic division. Thus, there is a delay of one cell cycle for the retroviral marker as compared with ${ }^{3} \mathrm{H}$-thymidine, and there is the important difference that infectable cells are restricted to those in contact with the cerebral ventricles. By injecting retroviral suspensions into rat ventricles between E14 and E19, we have been able to mark the following categories of cells: (1) nonpyramidal neurons, pyramidal neurons, and glia, following injections between E14 and E1 7 (comparable to E15E1 $8{ }^{3} \mathrm{H}$-thymidine injections); (2) pyramidal neurons and glia, after injections between E18 and E20 (comparable to E19-E21 ${ }^{3} \mathrm{H}$-thymidine injections); and (3) only glia elements following injections at E2 1 or later (comparable to E22 ${ }^{3} \mathrm{H}$-thymidine injections).

Other investigators (Fujita, 1966; Miller, 1985), who injected ${ }^{3} \mathrm{H}$-thymidine betwecn E14 and E20, marked the last division of pyramidal and nonpyramidal neurons, but not glia. According to ${ }^{3} \mathrm{H}$-thymidine studies, the majority of cortical glia are generated in the perinatal and postnatal periods (Fujita, 1966; Mares and Brückner, 1978; Skoff and Knapp, 1991). Differences in these results, together with the above-mentioned peculiarities of the two techniques, could mean that (1) progenitors of nonpyramidal cells divide belween E14 and E20 but are localized in the ventricular zone only until E18, (2) progenitors of pyramidal neurons divide between E14 and E20 and are localized in the ventricular zone for the entire period, and (3) progenitors of glial cells divide between E14 and a stage after birth and are localized in the ventricular zone for the same period, but their divisions produce glia only from E20.

These observations could support a model of sequential production of committed progenitor cells from a common multipotent progenitor (see Gray and Sanes, 1992, for a similar model in the optic tectum), with the progenitor of the nonpyramidal neurons produced first, then that of the pyramidal neurons and, finally, the glial progenitor. A rare multipotent progenitor has been identified in microcultures of isolated ventricular zone cells (Temple, 1989), together with progenitors committed to the neuronal or glial lineage. Our data suggest that such a multipotential progenitor could be present in the ventricular zone until E17. To comply with a model where both multipotent and committed progenitors are localized in the rat ventricular zone over a long period, it is important to see it as a heterogeneous structure, where multipotent progenitors are continously disappearing in giving rise to the committed progenitors of the various cell types.

\section{Lineage-independent choice of calcium-binding protein}

The above discussion points to a lineage-dependent control of cell phenotype. However, we have not been able to find a lineage relationship for the expression of calcium-binding proteins in cortical nonpyramidal neurons. Calb, Parv, and $\mathrm{Cr}$ are found in different subsets of neurons in the rat cerebral cortex, with only partial overlap (for review, see Baimbridge et al., 1992). Apart from being excellent markers of subpopulations of non- 
pyramidal neurons, their presence has been correlated with a variety of functions, all connected with intracellular calciun buffering and mobilization (Blaustein, 1988; Baimbridge et al., 1992). A strong correlation has been demonstrated between the occurrence of Parv and the fast firing propcrties of hippocampal interneurons (Kawaguchi et al., 1987). Recently, the distribution of Calb $D_{28 \mathrm{~K}}$ has been found to overlap with that of P-type calcium channels (Hillman et al., 1991). These data point to a correlation between calcium-binding proteins and the functional properties of the nonpyramidal neurons that express them. The present study has shown that such properties are not inherited by clonally related nonpyramidal neurons, but are likely to be induced by environmental cues that reach the neuron at its final location. These observations are in agreement with late appearance of immunohistochemically detectable calcium-binding proteins (Enderlin et al, 1987; Sánchez et al., 1990; Solbach and Celio, 1991) in cortical intrinsic neurons. Given the invariable association of certain afferent fibers in both cerebral cortex (serotoninergic, Hornung and Celio, 1992; GABAergic, Freund and Gulyás, 1991) and hippocampus (mossy fibers, Gulyás et al., 1992) with only nonpyramidal neurons containing one or the other calcium-binding protein, it is tempting to suggest that the expression of calcium-binding proteins in nonpyramidal neurons is driven by the kind of afferent fibers that establish contact with them. Whether and how the neurotransmitter(s) released in such contact may dictate the expression of a certain calcium-binding protein, and induce a complement of physiological properties in the contacted neuron, are not known and should be looked for in the organization of the genes for each of these calcium-binding proteins.

While this finding indirectly confirms that the phenotypic homogeneity of neuronal clusters found in our experiments was not based on an incorrect sampling of our material, it indicates how the shaping of the cerebral cortex takes place through a combination of mechanisms that includes genetic determination and environmental cues.

\section{References}

Altman J, Bayer SA (1990) Vertical compartmentation and cellular tranformations in the germinal matrices of the embryonic rat cerebral cortex. Exp Neurol 107:23-35.

Arimatsu Y, Miyamoto M, Nihonmatsu I, Hirata K, Uratami Y, Hatanaka Y, Takaguchi-Hayashi K (1992) Early regional specification for a molccular ncuronal phenotype in the rat ncocortcx. Proc Natl Acad Sci USA 89:8879-8883.

Austin CP, Cepko CL (1990) Cellular migration patterns in the developing mouse cerebral cortex. Development 110:713-732.

Baimbridge KG, Celio MR, Rogers JH (1992) Calcium-binding proteins in the nervous system. Trends Neurosci 15:303-308.

Barbe MF, Levitt P (1991) The early commitment of fetal neurons to the limbic cortex. J Neurosci 11:519-533.

Barfield JA, Parnavelas JG, Luskin MB (1990) Separate progenitor cells give rise to neurons, astrocytes and oligodendrocytes in the rat cerebral cortex. Soc Neurosci Abstr 16:1272.

Berry M, Rogers AW (1965) The migration of neuroblasts in the developing cerebral cortex. J Anat 99:691-709.

Blanton MG, Kriegstein AR (1991) Appearance of putative amino acid neurotransmitters during differentiation of neurons in embryonic turtle cerebral cortex. J Comp Neurol 310:571-592.

Blaustein MP (1988) Calcium transport and buffering in neurons. Trends Neurosci 11:438-443.

Buse E (1990) Generation of GABA-synthesizing nerve cells cultured from embryonic cortex cerebri of mice with and without cell-to-cell contacts. Anat Embryol (Berl) 182:151-160.

Cavanagh ME, Parnavelas JG (1988) Development of somatostatin immunoreactive neurons in the rat occipital cortex: a combined im- munocytochemical-autoradiographic study. J Comp Neurol 268:112.

Celio MR (1990) Calbindin D-28K and parvalbumin in the rat nervous system. Neuroscience 35:375-475.

Cobas A, Fairén A, Alvarez-Bolado G, Sánchez MP (1991) Prenatal development of the intrinsic neurons of the rat neocortex: a comparative study of the distribution of GABA-immunoreactive cells and the $\mathrm{GABA}_{\mathrm{A}}$ receptor. Neuroscience 40:375-397.

Conti F, Rustioni A, Petrusz P, Towle AC (1987a) Glutamate-positive neurons in the somatic sensory cortex of rats and monkeys. J Neurosci 7:1887-1901.

Conti F, Rustioni A, Petrusz P (1987b) Co-localization of glutamate and aspartate immunoreactivity in neurons of the rat somatic sensory cortex. In: Excitatory amino acid transmission (Hicks TP, Lodge D, McLennan H, eds), pp 169-172. New York: Liss.

DeFelipe J, Jones EG (1992) High-resolution light and electron microscopic immunocytochemistry of colocalized GABA and calbindin D-28K in somata and double bouquet cell axons of monkey somatosensory cortex. Eur J Neurosci 4:46-60.

Demeulemeester H., Vandesande F, Orban GA, Heizmann CW, Pochet $R$ (1989) Calbindin D-28K and parvalbumin immunoreactivity is confined to two separate neuronal subpopulations in the cat visual cortex, whereas partial coexistence is shown in the dorsal lateral geniculate nucleus. Neurosci Lett 99:6-11.

Dori I, Petrou M, Parnavelas JG (1989) Excitatory transmitter amino acid-containing neurons in the rat visual cortex: a light and electron microscopic immunocytochemical study. J Comp Neurol 290:169184.

Dori I, Dinopoulos A, Cavanagh ME, Parnavelas JG (1992) Proportion of glutamate- and aspartate-immunoreactive neurons in the efferent pathways of the rat visual cortex varies according to the target. J Comp Neurol 319:191-204.

Enderlin S, Norman AW, Celio MR (1987) Ontogeny of the calcium binding protein calbindin $\mathrm{D}-28 \mathrm{~K}$ in the rat nervous system. Anat Embryol (Berl) 177:15-28.

Erdö SL, Woolf JR (1989) A comparison of the postnatal changes in aspartate and glutamate levels in cerebral cortex of the rat. Neurosci Res Commun 4:51-56.

Fagg GE, Foster AC (1983) Amino acid neurotransmitters and their pathways in the mammalian central nervous system. Neuroscience 9:701-719.

Fields-Berry SC, Halliday AL, Cepko CL (1992) A recombinant retrovirus encoding alkaline phosphatase confirms clonal boundary assignment in lineage analysis of murine retina. Proc Natl Acad Sci USA 89:693-697.

Freund TF, Gulyás AI (1991) GABAergic interneurons containing calbindin D28K or somatostatin are major targets of GABAergic basal forebrain afferents in the rat neocortex. J Comp Neurol 314:187-199.

Fujita S (1966) Application of light and electron microscopic autoradiography to the study of cytogenesis of the forebrain. In: Evolution of the forebrain (Hassler R, Stephan H, eds), pp 180-196. Stuttgart: Thieme.

Galileo DS, Gray GE, Owens GC, Majors J, Sanes JR (1990) Neurons and glia arise from a common progenitor in chicken optic tectum: demonstration with two retroviruses and cell type-specific antibodies. Proc Natl Acad Sci USA 87:458-462.

Gray GE, Sanes JR (1991) Migratory paths and phenotypic choices of clonally related cells in the avian optic tectum. Neuron 6:211-225.

Gray GE, Sanes JR (1992) Lineage of radial glia in the chick optic tectum. Development 114:271-283.

Gray GE, Glover JC, Majors J, Sanes JR (1988) Radial arrangment of clonally related cells in the chick optic tectum: lineage analysis with a recombinant retrovirus. Proc Natl Acad Sci USA 85:73567360 .

Gray GE, Leber SM, Sanes JR (1990) Migratory patterns of clonally related cells in the developing central nervous system. Experientia 46: 929-940.

Grove EA, Kirkwood TBL, Price J (1992) Neuronal precursor cells in the rat hippocampal formation contribute to more than one cytoarchitectonic area. Neuron 8:217-229.

Grove EA, Williams BP, Li D-Q, Hajihosseini M, Friedrich A, Price J (1993) Multiple restricted lineages in the embryonic rat cerebral cortex. Development 117:553-561.

Gulyás AI, Miettinen R, Jacobowitz DM, Freund TF (1992) Calretinin is present in non-pyramidal cells of the rat hippocampus-I. A new 
type of neuron specifically associated with the mossy fibre system. Neuroscience 48:1-27.

Halliday AL, Cepko CL (1992) Generation and migration of cells in the developing striatum. Neuron 9:15-26.

Hendry SHC, Schwark HD, Jones EG, Yan J (1987) Numbers and proportions of GABA-immunoreactive neurons in different areas of monkey cerebral cortex. J Neurosci 7:1503-1519.

Hepler JR, Toomin CS, McCarthy KD, Conti F, Battaglia G, Rustioni A, Petrusz P (1988) Characterization of antisera to glutamate and aspartate. J Histochem Cytochem 36:13-22.

Hillman D, Chen S, Aung TT, Cherksey B, Sugimori M, Llinás RR (1991) Localization of P-type calcium channels in the central nervous system. Proc Natl Acad Sci USA 88:7076-7080.

Hornung J-P, Celio MR (1992) The selective innervation by serotoninergic axons of calbindin-containing interneurons in the neocortex and hippocampus of the marmoset. J Comp Neurol 320:457-467.

Huff R, Furst A, Mahowald AP (1989) Drosophila embryonic neuroblasts in culture: autonomous differentiation of specific neurotransmitters. Dev Biol 134:146-157.

Jones EG, Hendry SHC (1989) Differential calcium binding protein immunoreactivity distinguishes classes of relay neurons in monkey thalamic nuclei. Eur J Neurosci 1:222-246.

Kägl U, Berchtold MW, Heizmann CW (1987) $\mathrm{Ca}^{2+}$-binding protein parvalbumin in rat testis: characterization, localization and expression during development. J Biol Chem 262:7314-7320.

Kawaguchi Y, Katsumaru H, Kosaka T, Heizmann CW, Hama K (1987) Fast spiking cells in rat hippocampus $\left(\mathrm{CA}_{1}\right.$ region) contain the calcium-binding protein parvalbumin. Brain Res 416:369-374.

Kirkwood TBL, Price J, Grove EA (1992) The dispersion of neuronal clones across the cerebral cortex. Science 258:317.

Korbo L, Pakkenberg B, Ladefoged O, Gundersen HJG, Arlien-Søborg $P$, Pakkenberg $H$ (1990) An efficient method for estimating the total number of neurons in rat brain cortex. J Neurosci Methods 31:93100.

Krieg WJS (1946a) Connections of the cerebral cortex. I. The albino rat. A. Topography of the cortical areas. J Comp Neurol 84:221-275.

Krieg WIS (1946b) Connections of the cerebral cortex. I. The albino rat. B. Structure of the cortical areas. J Comp Neurol 84:277-324.

Lauder JM, Han VKM, Henderson P, Verdoorn T, Towle AC (1986) Prenatal ontogeny of the GABAergic system in the rat brain: an immunocytochemical study. Neuroscience 19:465-493.

Leber SM, Sanes JR (1990) Migration of clonally related cells in the developing chick spinal cord. Soc Neurosci Abstr 16:803.

Leber SM, Breedlove SM, Sanes JR (1990) Lineage, arrangment, and death of clonally related motoneurons in chick spinal cord. J Neurosci 10:2451-2462.

Levitt $P$ (1984) A monoclonal antibody to limbic system neurons. Science 223:352-355.

Lledo P-M, Somasundaram B, Morton AJ, Emson PC, Mason WT (1992) Stable transfection of calbindin $\mathrm{D}_{28 \mathrm{~K}}$ into the $\mathrm{GH}_{3}$ cell line alters calcium currents and intracellular calcium homeostasis. Neuron 9:943-954.

Luskin MB, Shatz CJ (1985) Neurogenesis of the cat's primary visual cortex. J Comp Neurol 242:611-631.

Luskin MB, Pearlman AL, Sanes JR (1988) Cell lineage in the cerebral cortex of the mouse studied in vivo and in vitro with a recombinant retrovirus. Ncuron 1:635-647.

Luskin MB, Parnavelas JG, Barfield JA (1993) Neurons, astrocytes and oligodendrocytes of the rat cerebral cortex originate from separate progenitor cells: an ultrastructural analysis of clonally related cells. J Neurosci 13:1730-1750.

Mares V, Brückner G (1978) Postnatal formation of non-neuronal cells in the rat occipital cerebrum: an autoradiographic study of the time and space pattern of cell division. J Comp Neurol 177:519-528.

Marin-Padilla M (1992) Ontogenesis of the pyramidal cells of the mammalian neocortex and developmental cytoarchitectonics: a unifying theory. J Comp Neurol 321:223-240.

Martinez S, Puelles L, Alvarado-Mallart RM (1992) Tangential neuronal migration in the avian tectum: cell type identification and mapping of regional differences with quail/chick homotopic transplants. Dev Brain Res 66:153-163.

Mattson MP (1988) Neurotransmitters in the regulation of neuronal cytoarchitecture. Brain Res Rev 13:179-212.

Mallson MP, Kater SB (1989) Excitatory and inhibitory neurotransmitters in the generation and degeneration of hippocampal neuroarchitecture. Brain Res 478:337-348.
Maxwell MH (1978) Two rapid and simple methods used for the removal of resin from $1.0 \mu \mathrm{m}$ thick epoxy sections. J Microsc 112: 253-255.

McConnell SK, Kaznowski CE (1991) Cell cycle dependence of laminar determination in developing neocortex. Science 254:282-285.

McDonald JW, Johnston MV (1990) Physiological and pathophysiological roles of excitatory amino acids during central nervous system development. Brain Res Rev 15:41-70.

Meinecke DL, Peters A (1987) GABA immunoreactive neurons in rat visual cortex. J Comp Neurol 261:388-404.

Miller MW (1985) Cogeneration of retrogradely labeled corticocortical projection and GABA-immunoreactive local circuit neurons in cerebral cortex. Dev Brain Res 23:187-192.

Mione MC, Danevic C, Cavanagh ME, Boardman P, Parnavelas JG (1992) Neurotransmitter expression in clonally related neurons in the rat cerebral cortex. Soc Neurosci Abstr 18:1111.

Ottersen OP, Storm-Mathisen J (1984) Neurons containing or accumulating transmitter amino acids. In: Handbook of chemical neuroanatomy, Vol 3, Classical transmitters and transmitter receptors in the CNS, Pt II (Björklund A, Hökfelt T, Kuhar MJ, eds), pp 141246. Amsterdam: Elsevier.

Parnavelas JG, Luder R, Pollard SG, Sullivan K, Lieberman AR (1983) A qualitative and quantitative ultrastructural study of glial cells in the developing visual cortex of the rat. Philos Trans R Soc Lond [Biol] 301:55-84.

Parnavelas JG, Barficld JA, Franke E, Luskin MB (1991) Separate progenitor cells give rise to pyramidal and nonpyramidal neurons in the rat telencephalon. Cereb Cortex 1:463-468.

Price J, Thurlow L (1988) Cell lineage in the rat cerebral cortex: a study using retroviral-mediated gene transfer. Development 104:473482.

Price J, Turner D, Cepko C (1987) Lineage analysis in the vertebrate nervous system by retrovirus-mediated gene transfer. Proc Natl Acad Sci USA 84:156-160.

Price J, Williams B, Grove EA (1992) The generation of cellular diversity in the cerebral cortex. Brain Pathol 2:23-29.

Raedler E, Raedler A, Feldhaus S (1980) Dynamic aspects of neocortical histogenesis in the rat. Anat Embryol (Berl) 158:253-269.

Rakic P (1974) Neurons in the rhesus monkey visual cortex: systematic relation between time of origin and eventual disposition. Science 183: 425-427.

Redburn DA, Schousboe A (1987) Neurotrophic activity of GABA during development. New York: Liss.

Reh TA (1992) Generation of neuronal diversity in the vertebrate retina. In: Determinants of neuronal identity (Shankland $M$, Macagno EK, eds), pp 433-467. San Diego: Academic.

Rickmann M, Chronwall BM, Wolff JR (1977) On the development of non-pyramidal neurons and axons outside the cortical plate: the early marginal zone as a pallial anlage. Anat Embryol (Berl) 151:285307.

Rockel AJ, Hiorns RW, Powell TPS (1980) The basic uniformity in structure of the neocortex. Brain 103:221-244.

Sánchez MP, Frassoni C, Fairén A, Alvarez-Bolado G, Spreafico R (1990) Expression of calbindin and parvalbumin during prc- and postnatal development of the rat cerebral cortex. Eur J Neurosci [Suppl] 3:284.

Sanes JR, Rubenstein JLR, Niculas J-F (1986) Use of a recombinant retrovirus to study post-implantation cell lineage in mouse embryos. EMBO J 5:3133-3142.

Schwaller B, Hunziker W, Buchwald P, Celio MR (1993) Production of an antiserum against calretinin. Cell Calcium, in press.

Shankland M, Martindale MQ (1992) Segmental differentiation of lineally homologous neurons in the central nervous system of the leech. In: Determinants of neuronal identity (Shankland M, Macagno ER, eds), pp 46-77. San Diego: Academic.

Sillito AM (1984) Functional considerations of the operation of GABAergic inhibitory processes in the visual cortex. In: Cerebral cortex, Vol 2, Functional properties of cortical cells (Jones EG, Peters $\Lambda$, eds), pp 91-117. New York: Plenum.

Skoff P, Knapp PE (1991) Division of astroblasts and oligodendroblasts in postnatal rodent brain: evidence for separate astrocyle and oligodendrocyte lineages. Glia 4:161-174.

Solbach S, Celio MR (1991) Ontogeny of the calcium binding protein parvalbumin in the rat nervous system. Anat Embryol (Berl) 184: 103-124.

Sternberg PW, Liu K, Chamberlin HM (1992) Specification of neu- 
ronal identity in Caenorhabditis elegans. In: Determinants of neuronal identity (Shankland M, Macagno ER, eds), pp 1-45. San Diego: Academic.

Stichel CC, Müller HW (1991) Dissociated cell culture of rat cerebral cortical neurons in serum-free, conditioned media: GABA-immunopositive neurons. Dev Brain Res 64:145-154.

Streit P (1984) Glutamate and aspartate as transmitter candidates for systems of the cerebral cortex. In: Cerebral cortex, Vol 2, Functional properties of cortical cells (Jones EG, Peters A, eds), pp 119-143. New York: Plenum.

Takahashi T, Nowakowski RS, Caviness VS Jr (1993) Cell cycle parameters and patterns of nuclear movement in the neocortical proliferative zone of the fetal mouse. J Neurosci 13:820-833.

Temple S (1989) Division and differentiation of isolated CNS blast cells in microculture. Nature 340:471-473.

Traub RD, Miles R, Wong RKS (1987) Models of synchronized hippocampal burst in the prescnce of inhibition. I. Single population events. J Neurophysiol 58:739-751.

Turner DL, Cepko CL (1987) A common progenitor for neurons and glia persists in rat retina late in development. Nature 328:131-136.

Turner DL, Snyder EY, Cepko CL (1990) Lineage-independent determination of cell type in the embryonic mouse retina. Neuron $4: 833$ 845.

Van Brederode JFM, Mulligan KA, Hendrickson AE (1990) Calciumbinding proteins as markers of subpopulations of GABAergic neurons in monkey striate cortex. J Comp Neurol 298:1-22.

Van Brederode JFM, Helliesen MK, Hendrickson AE (1991) Distribution of the calcium hinding proteins parvalbumin and calbindinD-28K in the sensorimotor cortex of the rat. Neuroscience $44: 157-$ 171.
Van Eden CG, Mrzljak L, Voorn P, Uylings HBM (1989) Prenatal development of GABA-ergic neurons in the neocortex of the rat. J Comp Neurol 289:213-227.

Vercelli A, Assal F, Innocenti GM (1992) Emergence of callosally projecting neurons with stellate morphology in the visual cortex of the kitten. Exp Brain Res 90:346-358.

Waechter RV, Jaensch B (1972) Generation times of the matrix cells during embryonic brain development: an autoradiographic study in rats. Brain Res 46:235-250.

Walsh C, Cepko CL (1988) Clonally-related cortical cells show several migration patterns. Science 241:1342-1345.

Walsh C, Cepko CL (1992) Widespread dispersion of neuronal clones across functional regions of the cerebral cortex. Science 255:434-440.

Walsh C, Cepko CL (1993) Clonal dispersion in proliferative layers of developing cerebral cortex. Nature 362:632-635.

Williams RW, Goldowitz D (1992) Lineage versus environment in cmbryonic retina: a revisionist pcrspective. Trends Neurosci 15:368373.

Witten JL, Truman JW (1991a) The regulation of transmitter expression in postembryonic lineages in the moth Manduca sexta. I. Transmitter identification and developmental acquisition of expression. J Neurosci 11:1980-1989.

Witten JL, Truman JW (1991b) The regulation of transmitter expression in postembryonic lineages in the moth Manduca sexta. II. Role of cell lineage and birth order. J Neurosci 11:1990-1997.

Zilles K (1985) The cortex of the rat. A stereotaxic atlas. Berlin: Springer. 